\title{
"We have ground to cover for each other": A case study of mentoring across Black sorority alumni in north central West Virginia
}

\author{
Elizabeth C. Dever \\ West Virginia University, ecdever@mix.wvu.edu
}

Follow this and additional works at: https://researchrepository.wvu.edu/etd

Part of the Gender and Sexuality Commons, Human Geography Commons, and the Race and Ethnicity Commons

\section{Recommended Citation}

Dever, Elizabeth C., "'We have ground to cover for each other": A case study of mentoring across Black sorority alumni in north central West Virginia" (2020). Graduate Theses, Dissertations, and Problem Reports. 7773.

https://researchrepository.wvu.edu/etd/7773

This Thesis is protected by copyright and/or related rights. It has been brought to you by the The Research Repository @ WVU with permission from the rights-holder(s). You are free to use this Thesis in any way that is permitted by the copyright and related rights legislation that applies to your use. For other uses you must obtain permission from the rights-holder(s) directly, unless additional rights are indicated by a Creative Commons license in the record and/ or on the work itself. This Thesis has been accepted for inclusion in WVU Graduate Theses, Dissertations, and Problem Reports collection by an authorized administrator of The Research Repository @ WVU. For more information, please contact researchrepository@mail.wvu.edu. 
"We Have Ground to Cover for Each Other"

A Case Study of Mentoring across Black Sorority Alumni

in North Central West Virginia

\begin{abstract}
Elizabeth Dever
Thesis Submitted to the Eberly College of Arts and Sciences at West Virginia University in partial fulfillment of the requirements for the degree of Master of Arts in the Department of Geology and Geography

\author{
Martina Angela Caretta, PhD., Chair \\ Cynthia Gorman, PhD. \\ Kasi Jackson, PhD.
}

Department of Geology and Geography
\end{abstract}

Morgantown, West Virginia

2020

Key Words: mentorship, Black sorority, feminist geography, Black geography, West Virginia

Copyright 2020 Elizabeth Dever 


\begin{abstract}
"We Have Ground to Cover for Each Other"

A Case Study of Mentoring across Black Sorority Alumni

in North Central West Virginia
\end{abstract}

Elizabeth Dever

Black sororities are much more than their stereotypes of stepping and partying. They are service organizations that have a deep impact on their communities and help shape the identities of their members. These organizations can be seen at Historically Black Colleges and Universities (HBCUs) and Predominately White Institutions (PWIs). Black sororities are different than their traditionally white counterparts because the majority of active time in membership occurs after graduation. This thesis utilizes a case study of Black sororities in North Central West Virginia and West Virginia University. In spaces lacking in diversity and inclusion, Black sororities can serve as a means for women of color to find a sense of belonging and can help shape their identities as women of color. This thesis based on archival data analysis and semi-structured interviews investigates which forms of mentoring are enacted by Black sorority alumni members, and how such types of mentoring help to find that sense of belonging and identity formation for women of color. 


\section{Contents}

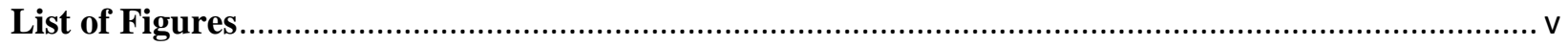

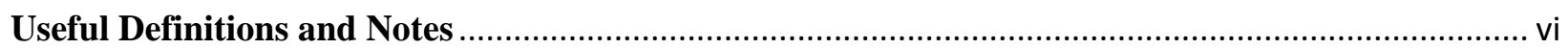

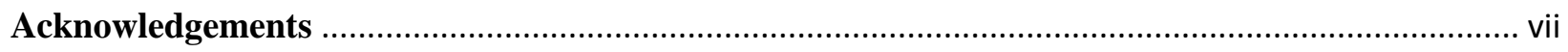

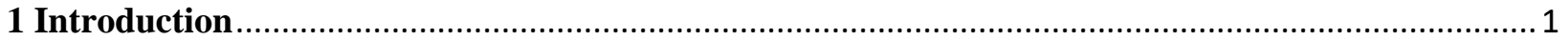

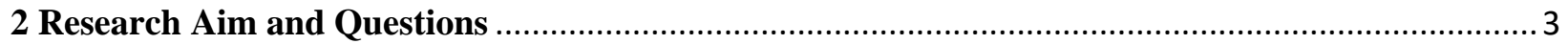

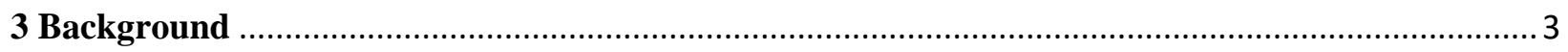

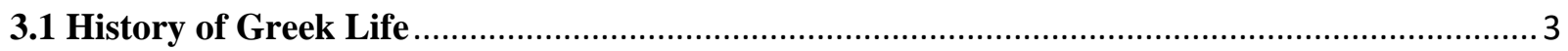

3.2 Black Greek Letter Organizations …....................................................................................

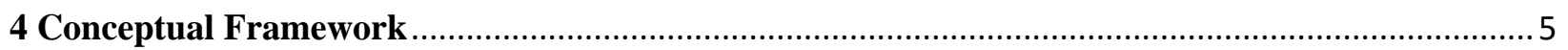

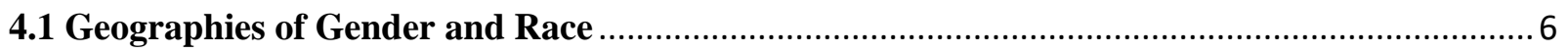

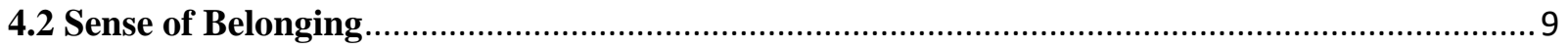

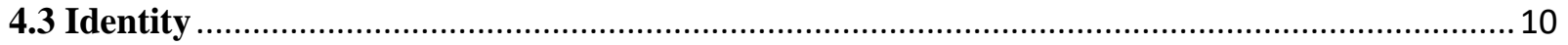

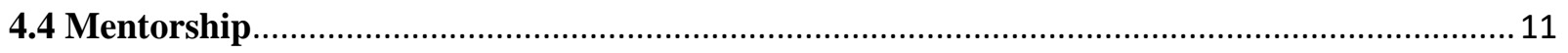

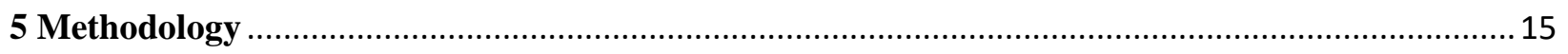

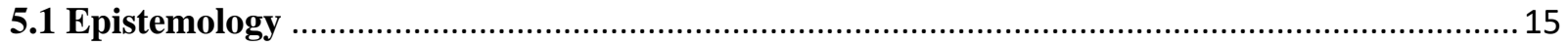

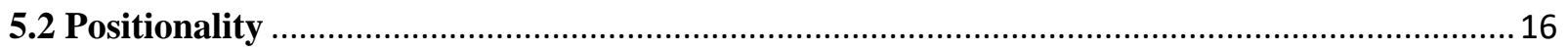

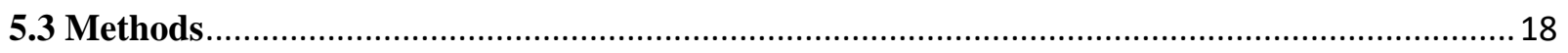

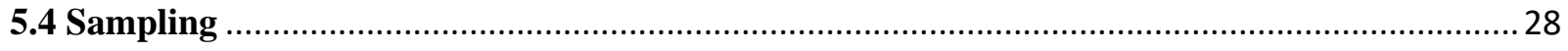

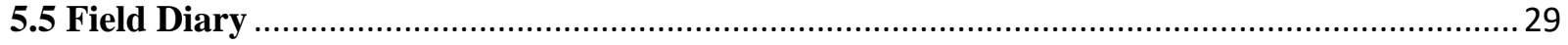

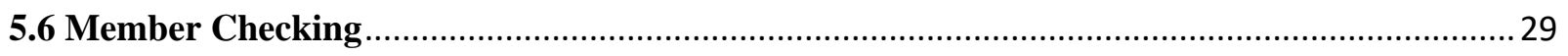

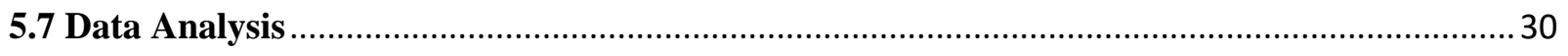

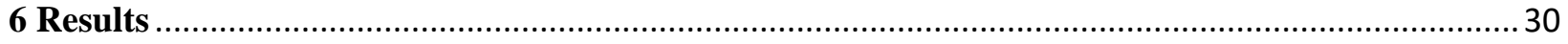

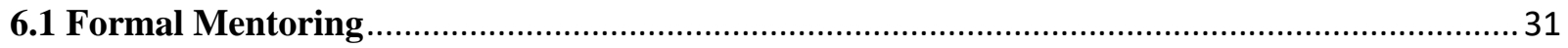

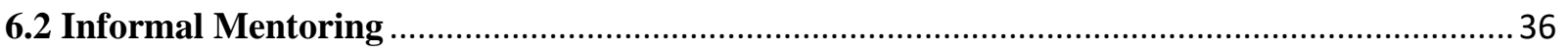

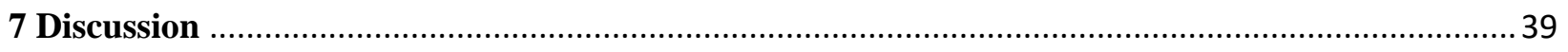

7.2 Formal Mentoring in Absence of Institutional Networks .................................................... 41

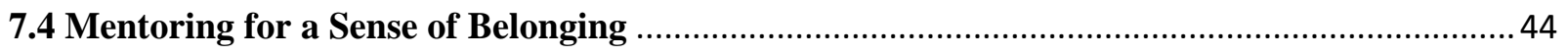

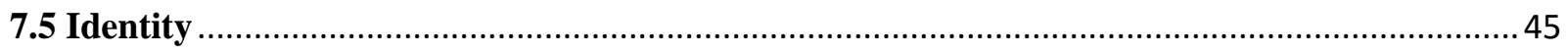

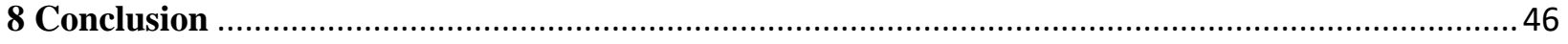

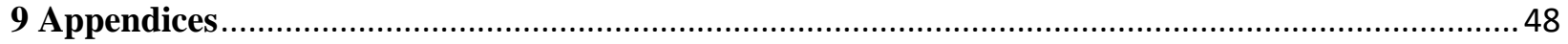




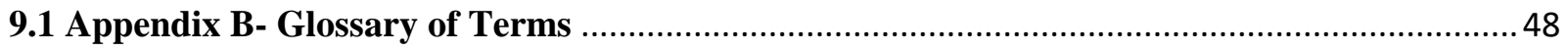

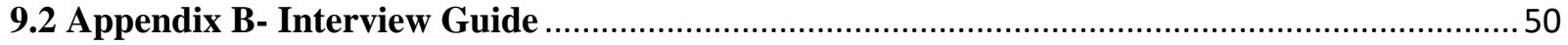

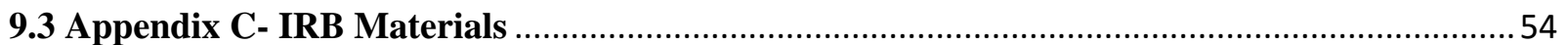

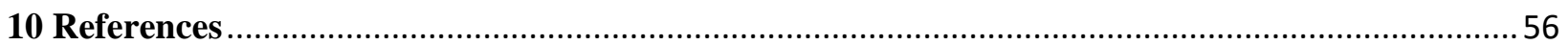




\section{List of Figures}

Figure 1 Overarching Conceptualization of the research organized from large to small scale....................12

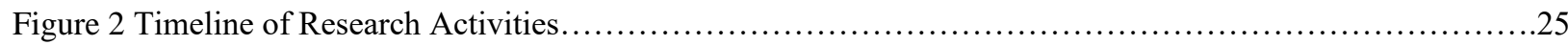

Figure 3 Newspaper article from 1991 outlining the differences between Black and White Greek Life..............27

Figure 4 Napkins and place card from a symposium on intercultural relationships

hosted by Alpha Kappa Alpha and in attendance Zeta Phi Beta and Phi Beta Sigma.........................................28

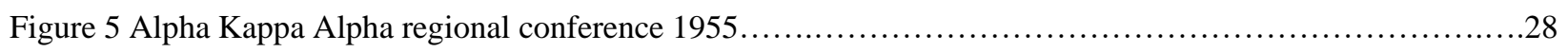

Figure 6 Picture of Alpha Kappa Alpha women at a social gathering in the 1970's,

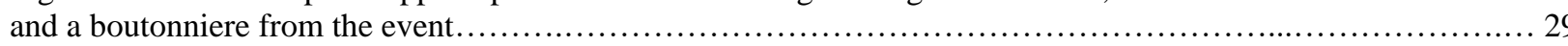

Figure 7 Alpha Kappa Alpha Sorority meeting agenda from January 1959

which entails the agenda for the meeting as well as future and current projects.

Figure 8 Alpha Kappa Alpha Members travel to California from

Pittsburgh to Boule their international conference

Figure 9 Alpha Kappa Alpha Meeting Minutes....................................................... 37

Figure 10: Program from the Alpha Kappa Alpha Boule in 1946

held in Los Angeles California with the theme was "Peace Building in the World

Figure 10: Program from the Alpha Kappa Alpha Boule in 1946 held in Los Angeles California 4 with the theme was "Peace Building in the World. 


\section{Useful Definitions and Notes}

\begin{tabular}{|c|c|}
\hline Term & Definition \\
\hline Black Sorority & $\begin{array}{l}\text { Historically Black service organization joined } \\
\text { predominately by women of color for leadership, } \\
\text { scholarship, service, and sisterhood. }\end{array}$ \\
\hline Traditional Sorority & $\begin{array}{l}\text { Historically white social organizations joined by } \\
\text { undergraduate women at colleges and universities } \\
\text { for the purposes of socializing, philanthropy, and } \\
\text { sisterhood }\end{array}$ \\
\hline National Panhellenic Council (NPC) & $\begin{array}{l}\text { Governing body of } 26 \text { member organizations of } \\
\text { collegiate chapters of sororities }\end{array}$ \\
\hline National Pan-Hellenic Council (NPHC) & $\begin{array}{l}\text { Governing body of nine member organizations of } \\
\text { both men's and women's traditionally Black } \\
\text { fraternities and sororities }\end{array}$ \\
\hline Predominately White Institution (PWI) & $\begin{array}{l}\text { Institution of higher education not designated as a } \\
\text { Historically Black College or University (HBCU) } \\
\text { prior to the Brown v. Board of Education supreme } \\
\text { court decision in } 1954\end{array}$ \\
\hline Financial Member & $\begin{array}{l}\text { Member of a sorority who has paid yearly dues to } \\
\text { the organization, but is not associated with a } \\
\text { particular chapter; often called member at large }\end{array}$ \\
\hline A note on the capitalization of 'Black' & $\begin{array}{l}\text { For the purposes of this research, 'Black' and } \\
\text { 'African American' are used interchangeably. I } \\
\text { have chosen to capitalize 'Black' and not 'white' } \\
\text { because the term Black indicates not only people of } \\
\text { African descent, but indicates a racial identity and } \\
\text { history of African Americans (Price, 2019) }\end{array}$ \\
\hline Membership Selection & $\begin{array}{l}\text { Process in which sorority women select their } \\
\text { prospective new members. Process differs between } \\
\text { the historically Black and traditional sororities }\end{array}$ \\
\hline Legacy & $\begin{array}{l}\text { A woman who has a biological connection to a } \\
\text { member of a particular organization such as a } \\
\text { mother, aunt, sister, or grandmother }\end{array}$ \\
\hline Philanthropy & $\begin{array}{l}\text { Refers to raising money for a cause through an } \\
\text { event or donation }\end{array}$ \\
\hline Service & $\begin{array}{l}\text { Refers to direct service to an organization or those } \\
\text { in need }\end{array}$ \\
\hline
\end{tabular}




\section{Acknowledgements}

I would first like to thank everyone who participated in the research for sharing a piece of your story with me, you all have inspired me to be a better woman. I would also like to thank those who supported me on this journey through graduate school. Thank you to my adviser and committee chair, Martina Angela Caretta. I couldn't be more thankful for the commitment and support you have showed me throughout the last three years, you have without a doubt been one of the most influential women in my life thus far. To my committee members Cynthia Gorman and Kasi Jackson for their guidance and expertise in your respective fields, and for pushing me to think in different ways. Thank you to my colleagues who I have embarked on this journey of graduate school with, I appreciate your constant support, laughs, and encouragement through it all. To Alanna Higgins, you have been a constant in my life throughout graduate school; thank you for your friendship, guidance, and support. To Bethani Turley for mentoring me through my first year of graduate school and allowing me to accompany you on your own research endeavors. To Brandon Rothrock, you have become a friend that I will always lean on and look to for support; thank you for reading and helping me along with this thesis. Lastly, I would like to thank the West Virginia University Department of Geology and Geography for their constant support throughout my undergraduate and graduate experience at WVU- not only for funding my education, but for every one of the students, professors, and staff who have made this experience a great one. 


\section{Introduction}

The questions of 'Who am I?' and 'Where do I belong?' cannot be isolated from one another. Each question contributes to what Antonish (2010) calls place-belongingness. These questions force one to recognize that a sense of belonging in a place contributes directly to the formation of identity. However, in order to feel such a belongingness, one needs to establish psychosocial, emotional, and interpersonal relationships with people, places, and things that make one feel at 'home' (Tuan, 1997). Though all humans have an inherent need to connect with one another, not every human has equal opportunity to make these connections. Due to structural racism and long-standing psychosocial struggles, women of color may have trouble navigating certain spaces in which the hegemonic structure has not or does not allow for equal opportunity, such as at universities (Henry, 2017).

At their inception, colleges and universities were created for and by white men, making the cycle of advancement for whites a stable practice in society. They suppressed opportunities for marginalized groups, and specifically, for the focus of this research, Black women. (McKenzie, 2012). For example, in 2017, the National Center for Education Statistics reported that out of the nearly 1.5 million faculty in degree-granting postsecondary institutions, only $3 \%$ of full-time faculty were Black women (U.S. Department of Education, 2019). Mentorship can be a solution to navigating these spaces; however, with a lack of Black women faculty, Black students may not have a mentor that shares in their experience of being a black woman (Patton and Harper, 2003). Due to the lack of representation of Black women full-time faculty, formal networks at the institutional scale are rarely forged.

Mentorship, for the context of this research, is conceptualized in two overarching categories: formal and informal mentoring. Formal mentoring includes networks which refer to having more than one mentor that provides advice in various aspects of home and work life (de Janasz and Sullivan, 2004; Sorcinelli and Yun, 2007). Another vein of formal mentorship is sponsorship (Sands, Parson, and Duane, 1991; Dixon-Reeves, 2003) which involves the sponsor advocating for structural change for the mentee such as with raises, job offers and other resources. Each of these types of mentoring can occur within educational or career settings. Informal mentorship emerges in the context of peer-peer mentoring which entails sharing experience and advice with peers of the same rank (Darwin and Palmer, 2011). Mentoring in this sense is also called psychosocial mentoring.

Informal peer relationships such as those formed in Greek Letter Organizations (GLOs) hold members accountable and promote success and leadership. Many Black women experience these relationships prior to college through their families, Black sorority members in their communities or other social programming such as mentoring programs or church mentoring (Domingue, 2015). Once exposed to the values of these organizations, they can influence 
personal and academic success as well as social aspects of college life. Depending on the institution, GLOs can provide a place and sense of belonging. These spaces (GLOs) have been shown to play a role in retention and graduation, especially for Black students (Kimbrough, 1995; Phillips, 2005; Neumann, 2008).

Black sororities hold the values of "racial uplift", education, service, mentorship, and leadership, with most members joining as alumnae post-graduation (Neumann, 2008). Harris, Barone and Finch note that "because the number of African American women in major leadership positions on college and university campuses is dismal at best, seeing other women of color in higher positions in professional organizations motivates graduate women and confirms to them that success and respect in their chosen professions are attainable" (2019, p. 18). After graduating, Black women can turn to Black sororities for positive role models and mentoring relationships which are more intricate than traditional mentoring relationships. The intricacy of these relationships lies in the history of West African cultural traditions which influenced early Black Americans. As Domingue states "[in this context] families functioned as micro-communities that fostered support networks in areas of caretaking, resource gathering, and protection" (2015:456). These relationships have been preserved through othermothering and the sorority organizational structure over time. As such, Black sororities serve as a means for women to perceive a sense of belonging in the spaces they inhabit.

Place can mean a mark on a map that can be identified via boundaries such as physical structures or landscape barriers. However, place in the context of human geography is much more complex, representing the geographical manifestation at various scales from the body to the largest human scale of the globe (Kaplan, 2018: 98). Place at the larger scale is determined by outside sources such as political boundaries, however, place at the scale of the body can be created through emotion which as Dyck notes, "widens the potential of constructing analytic categories more inclusive of the diversity of human experience" (2005, p. 236). Place itself is highly contested in its organization whether through borders, fence lines, or place that is occupied by a person. The organization of such space is deeply ingrained in the larger socioeconomic and political structure and more intricately entangled with "local economies, histories, and individuals to create unique settings for interaction between [others] and those who have traditionally inhabited a space" (Nelson and Hiemstra, 2008: 337). An examination of place allows for the analysis of how power functions, and for the parameters of this research, universities.

The legacy of the creation of place itself in this case PWI's is deeply entwined with the social politics at the time of inception; in this case the late 1800's, only two years after the Civil War ceased. The foundations of the University then continue a long line of discrimination and unequal opportunity. The establishment of a counter space or space of resistance is the exact reason why Black sororities came about: they allow Black women to 'carve out' a space of their own (Neumann, 2008). This thesis explores how such organizations provide a means for women 
to gain mentorship experiences in predominately white masculine spaces which in turn, aid in their sense of belonging and identity development.

The following research fills a gap in geographic literature in the context of mentorship, specifically in predominately white spaces. Much research has been published in various contexts of mentoring such as a feminist praxis (Moss, Debres, Cravey, Hyndman, Hirschboeck, and Masucci, 1999; Datta and Lund, 2018; Moss, 2019) and mentoring for women of color mentoring (Kochan and Pascarelli, 2003; Patton and Harper, 2003; Mahtani, 2006). However, there have been few geographic projects that utilize Black sororities as a vessel for analyzing how mentorship can contribute to a sense of belonging and identity for women of color in predominately white spaces. Much literature focuses on mentorship in educational institutions rather than the entirety of an institution's realm (i.e. the local community and life postgraduation).

\section{Research Aim and Questions}

The aim of this research is to explore how mentorship (i.e. peer-peer and networking) via membership in a Black sorority alumnae chapters shapes women's identity and sense of belonging. This aim has been fulfilled by investigating the following research questions:

1. What types of mentorship are enacted in Black sorority alumnae chapters?

2. How does mentorship enacted through Black sororities shape women's sense of belonging in society?

3. How does mentorship created through Black sororities shape women's identity?

\section{Background}

In this section I provide background information on the origins and history of Greek life in both traditional and Black Greek letter organizations.

\subsection{History of Greek Life}

Traditional women's sororities date back to 1867 , at a time when only five state universities admitted women, groups of women came together to model secret societies like that of their male counterparts. Although sororities have a lasting history of philanthropic service, leadership, scholarship and friendship, they also have a lesser known and deeply rooted history in segregation and racism. The underlying framework of white Greek organizations has been both de facto and de jure segregation through the implementation of white clauses which barred the recruitment of women of color for membership (Harris, Barone, and Finch, 2019). These clauses were practiced explicitly up until the 1970s, but de facto discrimination still presents today. The legacy that follows these modes of segregation highlight why these traditional Greek 
organizations continue to be some of the most segregated spaces at PWI's (Harper and Hurtado, 2007)

The first traditional sorority on campus at West Virginia University emerged in 1899. Following integration in 1954, the first Black sorority was established on campus. Alpha Kappa Alpha was established in 1973, and a second Black sorority, Delta Sigma Theta was established ten years later. The most recent Black sorority to come to campus is Zeta Phi Beta, which chartered in 1993. Today, there are eight traditional and two Black sororities on campus.

Notably, there is a separation of governing bodies for all Greek Life internationally. There are three governing bodies including the National Pan-Hellenic Council (NPHC), the National Panhellenic Conference (NPC) and the National Interfraternity Council (NIC). Both NPC and NIC groups govern traditional single-sex organizations for women and men respectively. The NPC has 26-member organizations, and the NIC has 70 international associated chapters. The NPHC however, governs nine organizations often called the "Divine Nine" and are a combination of both women's and men's Black Greek Letter Organizations.

\subsection{Black Greek Letter Organizations}

Black Greek Letter Organizations formed because Black men and women wanted the same benefits that Greek life offered white students such as professional development, leadership experience and friendship. Thus, the first historically black sorority formed at Howard University, Alpha Kappa Alpha (AKA) in 1908. The founding of this organization parallels that of its male counterpart, Alpha Phi Alpha that formed at Howard one year prior" (McKenzie, 2012).

The second Black sorority, Delta Sigma Theta (Delta or DST) was created in 1913 by prior members of AKA of whom believed that the organization should be more service-oriented. These women aimed to conquer social concerns of the time that influenced the rights of Black women. They yearned to relate to like-minded women across the country and wanted to establish an organization that would allow for expansion to other universities. The Deltas brother organization, Omega Psi Phi advised them in creating a national organization (McKenzie, 2012). Two months after their official founding date of March 3, 1913, members of Delta marched down Pennsylvania Avenue for the Women's Suffrage Movement.

Leadership is not a new concept learned while in the organizations themselves. Black sororities have a deeply rooted legacy within individual families. In fact, Black sororities are an extension of both African cultural traditions, and resistance to intersectional oppression (Phillips, 2005). The extended families of slaves were female centered, where the nature of slavery required mother-child bonds to be of utmost priority as a means of stability and survival (Phillips, 2005). Phillips draws from Shimkin and Frate's 1979-piece Extended Family in Black Society to 
illustrate that parallels can be drawn regarding extended families and membership, because of their shared commitment to lifelong membership in the unit. Once a woman is initiated into the sorority, she is a member until her death (2005: 346). This legacy has allowed Black women to pursue fields of study in higher education in fields not explored by their ancestors and has allowed them to devote their lives to leadership in the Black community (Phillips, 2005; Neumann, 2008). Black sororities not only have a legacy of leadership, but also a legacy of activism and political organizing. The most notable examples are organizing during the Civil Rights Movement with the most prestigious members being Mary McLeod Bethune and Mary Church Terrell of Delta Sigma Theta, and Norma Boyd, Rosa Parks and Coretta Scott King of Alpha Kappa Alpha (Whaley, 2010).

\section{Conceptual Framework}

\section{Geography and Gender/Race \\ Mentorship (Formal and Informal)}

Sense of Belonging

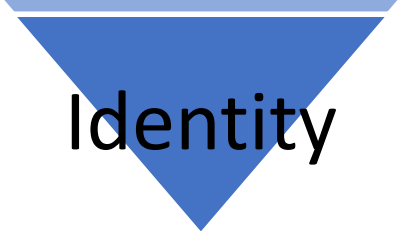

Figure 1 Overarching Conceptualization of the research organized from large to small scale

I situate this research within the geographic sub disciplines of feminist and Black geographies, in relation to the concepts of belonging and identity formation. Both feminist geography and Black geography focus on the embodied dimensions of belonging and identity. Black geography in particular aids in contextualizing the embodied sense of belonging for Black women in Predominately White Spaces (PWS). Because both frameworks aim to analyze marginalized populations - in sometimes contrasting ways - I will not focus solely on the sub-disciplines specifically but how each sub discipline has contributed to the analysis. Specifically, I will provide context for the major themes that emerged in the findings- mentorship, sense of belonging, and identity in the context of a PWI. 


\subsection{Geographies of Gender and Race}

Feminist geography stemmed out of critiquing the traditionally white and male discipline of geography in the 1970s (Rose, 1993). Women geographers began their research inquiries by focusing on adding gender and specifically women as a spatial lens of analysis (Alcoff, 1996). Early research in the 70s began by analyzing women's roles at the scale of the home, and then later by pushing back on masculinist ideals that embodied knowledge was not knowable. Prior to feminist theorizations of knowledge, the concept of the mind-body dualism, in which the mind is seen as a separate entity from the body, prevailed in the understanding of knowledge production. The philosophy of science of positivism was grounded on this dualistic nature which relied on principles of objectivity and falsification. These principles aimed to gain an understanding of the world through representation and generalizations rather than through introspection and reflexivity (Falconer- Al Hindi, and Kawabata, 2002).

Feminist geographers brought to light how traditionally valued knowledge was produced only in the public sphere-places such as universities (Bondi, 1993; McDowell, 1993), rather than in the private sphere-places such as the home (England, 2003). Only men had access to public spaces, hence only men's bodies and knowledge were valued. The white male body was conceptually constructed as a vessel for knowledge which could move between public and private spaces effortlessly. The mind was thought to be feminine, being associated with emotions and feelings interfering with seeking the Truth.

With the rejection of positivistic ideals came the concept of situated knowledge. This concept, coined by Haraway (1988) asserts that the object of knowledge is both agent and actor, rejects that knowledge is constructed without its own set of biases or agendas and asserts that knowledge is grounded on the contextual circumstances of the people living a certain phenomenon. Black feminists of the time such as Walker (1979) and Crenshaw (1989) focused on the experiences of Black women.

Later in the 1990s, feminist theorists argued that the body is a space of knowledge that is influenced by social and political forces, refuting the notion that women are incapable of producing knowledge (Longhurst, 2005). By recognizing the social and political factors affecting women, white feminists asserted that research should not be geared at generalizing the experiences of any one group. Such research however only addressed the concerns and needs of white women at the time. It was not until critical work by women of color, such as work done on intersectionality (Crenshaw, 1989), began to emerge that feminist research began to really encompass all women. Accordingly, the feminist movement aimed to become more inclusive of groups such as women of color and the LGBTQ+ community (Rose, 1993). 
Critical work by women of color contributed to knowledge by showing that oppression faced by marginalized groups is multidimensional (Valentine, 2005). During the early 90's Crenshaw coined the term intersectionality. Intersectionality focuses on how different aspects of identity interact and that it is impossible to isolate one identity aspect. Intersectionality does not only highlight the problems of exclusion but shows that a woman's experience is more than just the addition of sexism to racism. Intersectionality shows that Black women are constantly in flux navigating spaces where their collective experience is engrossed in one group or another even though they are experiencing discrimination which is more than the sum of their parts (Crenshaw, 1989). Black feminist thought more broadly takes this notion one step further to make sure that all women's bodies are spaces of knowledge, not just the traditional white feminist body challenged the notion that gender alone can be used to analyze oppression. Black women, such as Alice Walker argued that women of color tended to have more in common with Black men due to structural racism and prejudice, and so while white women were spearheading the feminist movement, Black women in the late 70s looked up to influential Black feminists such as Alice Walker who coined the term 'Womanism' (Walker, 1979). In the 1950s and 60s, Black women were heavily involved in local community organizing regarding the Civil Rights Movement. However, this movement was very masculinist, with Black women pushing back on the very gender norms that challenged the African American family structure (Roth, 2004).

Some African American women for example, argued that the home and the family acted as a place of refuge from oppression, not a space in which they felt oppressed, as white feminists had previously claimed for themselves (Roth, 2004). Black feminism aimed to break constructs of racist and sexist ideology through recreating society. This was done through both practical and intellectual means as a form of resistance while society aimed to make Black women's contributions invisible (Norwood, 2013). This idea of the creation of space through pragmatic resistance was a newer idea for feminist theory but has been deeply ingrained in the Black experience in the United States, a central theme from Black geographies.

During the early 1990s, Black geographic texts began to be published. It is a common misconception that Black geography is a 'new' strand within the discipline; however, this notion is exactly what Black geographies aims to critique. Geography itself has a deeply rooted history in colonialism, and as such, the voices of the Black population have been invisible and rendered unknowable (McKittrick, 2006). There are no spaces in our culture that are not inherently raced. As Delaney argues, race is "integral to the formation of all American spatialities at all scales of reference from the international to the corporeal" (2002, p. 7). Each physical space that is or has been created is predicated on the legacy of racism and discrimination especially in public spaces. Not only are physical spaces such as universities and cities raced, but so are unseen spaces. Certain voices such as people of color and other marginalized groups have been systematically excluded from the physical and metaphorical spaces within the field of human geography (Hawthorne \& Heitz, 2018: 150). The most prevalent exclusions today include racial 
microaggressions that are not committed with intent but reflect upon the prevalence and legacy that racism has on the academy (Joshi, McCutcheon, and Sweet, 2015). Though race is socially constructed, the effects of construction can be deeply personal to those it affects and in geographic spaces seem invisible to those whose ancestors have laid the groundwork (Berg, 2012). Black geographies are defined as "subaltern or alternative geographic patterns that work alongside and beyond traditional geographies and a site of terrain of struggle" (McKittrick 2006: 7). Black geographies do not just add Black voices to the discussion but enact a critique of liberal politics that deepens the analysis of why certain voices have been left out of the academic and mainstream narrative. The why in this case is the institutionalization of whiteness and what Joshi, McCutcheon and Sweet argue is what set in motion more obvious forms of racism such as slavery or Jim Crow, but is also repeated through microaggressions; these microaggressions transverse "invisible lines and boundaries" within geographies (2015, p. 301).

The concept of space has traditionally been presumed as something knowable. However, space is a conditional concept. If there is a knowable space, then there must exist an unknowable space; it is presumed by traditional geographies that Black bodies reside within this unknowable space. Space that is unknowable is deficient in material references and is explained through storytelling and spoken word rather than manifested in physical spaces (Brown, 2018). This 'unknowable' space, therefore, contributes to the identity of a person of color. Black geographies are then interested in making these space and bodies knowable, as well as black place making (McCutcheon, 2015). People of color can never "enjoy the privileges of whiteness" even when adopting cultural norms that have created geographies of power which operates in knowable spaces such as universities (Joshi, McCutcheon and Sweet, 2015: 302). These 'unknowable' spaces, however, are not only permeated by racism, but also the social ideologies that are predicated on power and hegemony through sexism, public-private ownership, and citizenship. These axes of power inherently create the spatiality of everyday life for people of color as being unseen or unknowable (Delaney, 2002). Because of this notion that Black bodies reside in unknowable space, Black women embrace sistership, and emotional care to create spaces of inclusion that shape a sense of resistance (Minnett, James-Gallaway, and Owens, 2019). It is not coincidental that invisible space is occupied by the every day lives of people of color in the United States. People of color also share this space with the normality of whiteness and how white privilege is maintained (hooks, 1992). The invisibility of whiteness allows, "whiteness itself to take on the appearance of normal [which in turn], facilitates the misrecognition of people, places, and situations that are raced as non-white as exceptional, if not abnormal" (2002, p.11). The sense of abnormality or 'othering' displays how race and space are mutually constructed.

Brown argues in her portfolio Black Feminisms that Black identity and sense of belonging is entangled with the transatlantic slave trade, colonialism, and modernity (Brown, 2018). Geography itself has helped to 'erase' Black place making because social identities (race, class, 
gender, sexuality) determine the patterns in which a person can exist in certain spaces (McKittrick, 2006). The erasure of Black place making then directly correlates with the social production of space; for space in the traditional sense in order to be made, humans must be placed in particular spaces based on their race (McKittrick, 2006). Boundaries that are created by those in power have lived and material manifestations in the daily lives of people of color who do not have the privilege or choice of not recognizing racism, because it permeates their past, present and future.

For every knowable space deemed by geographers, there is also an unknowable space that has been transversed by Black bodies since the creation of that space. Any space that can be thought of particularly in the United States that has been studied geographically. Geographies of belonging are geographies that are negotiated; they are decided through the hegemonic actors who work to reconstruct the idea of who and what belongs through their ontological, epistemological and material struggles of the everyday (Mee and Wright, 2009). Such hegemonic structures then decide who is an insider, and who is other. The subdisciplines highlighted above coalesce to form a unique perspective on Black feminist thought.

\subsection{Sense of Belonging}

Sense of belonging first began to emerge as a concept within geography in the 1970s through humanistic geography, specifically by Yi Fu Tuan. Tuan asserted that humans are not only a body, but also a mind and a spirit that are embodied and social creatures who need intimate spaces (Tuan, 1997). The concept of belonging itself has had contested definitions throughout time in the discipline. Several sub-disciplines of geography (cultural geographies, feminist geographies, black geographies, etc.) explore a sense of belonging however, there has not been one agreed upon definition. For example, there is no definition of belonging in one of the most cited human geography dictionaries (Gregory et al., 2009). One proposed definition for a sense of belonging is through what Antonish calls place-belongingness where one feels at 'home' (2010, p. 646). Home in this sense is not the same type of home studied by early feminist geographers, but the home as a symbolic space. This symbolic space is one as bell hooks notes, of "familiarity, comfort, security and emotional attachment" (2009, p. 213). This emotional attachment does not have to be specifically in the typical 'home' that one may have grew up in but can also serve as a space in which one creates that feels like 'home' which does not have to be a physical dwelling. Tuan also asserts this sense of belonging to not only being one of blood relation, but that those who are in close proximity to us as humans are as effective as blood in cementing bonds among people (Tuan, 1997).

A sense of belonging can emerge in different ways via different attachments to places, people, or things, which can vary from person to person (Gaither, 2017). This process itself is dynamic; as Yuval-Davis notes, there are three major levels to understanding the notion of belonging- social 
locations, attachment to collective and groupings, and ethical and political value systems (2009, p. 199). Social locations that contribute to a sense of belonging include of gender, sexuality, socioeconomic status, all of which are elements of one's positionality or standpoint that vary depending on the historical context. For example, there is a dualistic notion with each of the primary identifiers (i.e. gender, sexuality, socioeconomic status, race). The dualistic thinking has a legacy within hegemonic norms and senses of difference. One had to be either man or woman, homosexual or heterosexual, rich or poor, or Black or white. Identifications and emotional attachments contribute to a person's narrative that do not have to be broader social categories but are more individual attributes such as body image or other attributes that highlight the sense of self. Yuval-Davis also highlights the importance of not thinking of belonging as a story, but by looking at the story in a sense of how secure a person feels- those who feel threatened cannot feel a sense of belonging (2006, p. 202). For the majority of history, white men were the ones who decided whether or not someone fit in or was viewed as an other. Because this was determined by the hegemonic structure, ethical and political values of those who fit into space decided how a person was judged as inside the ingroup or the outgroup. As such, a person's concept of belonging is shaped by how the hegemonic society views their own personal values (Mackenzie, 2004). While Yuval-Davis (2009) conceptualizes a sense of belonging from the predeceasing framework, another framework is offered by Antonish.

Antonish (2010) provides five components that contribute to a feeling of place-belongingness that create a feeling of belonging for an individual including autobiographical, relational, cultural, economic, and legal. Autobiographical factors include 1: the experiences and memories that allow a person to attach to certain people, places, or things; 2 : relational factors including personal and social ties; 3 : cultural factors including language and customs that allow someone to attach to a particular place or culture; 4: economic factors allow a person to feel safe and stable in place; and 5: lastly legal factors such as citizenship and residency which can provide security. One place where one can create this sense of place-belongingness or 'home' is through the space of mentorship.

For the purposes of this thesis, I am adopting a combined definition of a sense of belonging from both Yuval-Davis (2006) and Antonish (2010). As such, there are various components that contribute to a person's sense of belonging including autobiographical, cultural, and social attachments. Autobiographical in the sense of a person's narrative of their self, cultural as in the persons view of themselves in relation to the hegemonic culture, and social attachments as in relation to their personal lives and politics.

\subsection{Identity}

Identity research has been a staple in the psychosocial sciences as early as the 1890s (Gaither, 2017). Present day definitions focus more on ingroup and outgroup relations; this definition has 
evolved greatly to include research on why and how our identities are formed. A surge in researching identities in the social sciences emerged following ethnic and regional movements, immigration, and geopolitics which challenged regions of the world to construct new and individual identities (Passi and Hakli, 2002). Social constructivists argue that identity emerges through experiences within particular sociogeographic contexts (Holloway, 2000). Prior to the 1990s, employment was a major factor in social status and identity (Green, 1998). However, if we form our identities off of our occupation, we are missing out on the majority of factors that contribute to identity over the lifespan.

Specifically, for the context of this research, I focus on racial identity and the broader identity literature. All members of society have a racialized identity, even those in the dominant demographic (Tatum, 1997). Factors that contribute to identity formation include gender, class religion, ethnicity, and sexuality, among other factors, that shape and distribute privilege unevenly in a hegemonic context. These dimensions of identity intersect and interact; we cannot look at identity formation without recognizing various dimensions of a person's identity (hooks, 1995; Ruddick, 1996). This intersectional approach as explained earlier through Crenshaw's framework (1989) is essential in knowing how an identity is formed as an overarching umbrella of various portions rather than one specific identity.

Feminist geography has looked at identity in relation to the construction of difference, or the 'other' (McDowell, 1993; Pratt and Hanson, 1994). Epistemologies and politics of identity formation are situated in each person's personal experience. No one experience for those in a particular identity category is the same. People are thus positioned in society according to the idea of difference determined by the hegemonic structure. Each individual's knowledge is distinct and set in place by social forces from the global to the local scale (McDowell, 1993). For those who are deemed 'other' such as migrant women, women of color, and the LGBTQ+ population are constantly transgressing boundaries in search of finding a sense of placebelongingness which helps to form their identity. One way to aid women in transgressing such boundaries is mentorship (Spivak, 1988; Mohanty, 1991).

\subsection{Mentorship}

Mentorship is defined as a broad flexible network of support where no one person is required to engage in such a relationship, so that actors may organically create connections through educational, career, and psychosocial mentoring (Sorcinelli and Yun, 2007). Groundbreaking studies regarding Black women's mentorship focus solely on mentoring in academia (Blackwell, 1983; Mumford, 1996). This study looks at the experiences of Black sorority members, all of which hold at least a bachelor's degree. Educational discrimination affects women of color disproportionally because of intersectional oppression (Henry, 2017). In challenging educational environments, it is crucial that those who have been seen as other by society have access to 
networks both formally (through educational, career, and institutional) and informally (psychosocial mentoring or peer mentorship) in order to create spaces of inclusivity (Grant and Zwier, 2011). Often, mentorship will take on various roles throughout a person's life that help to construct identity. Each mentoring relationship is contextual, complex, and unique for each mentor and mentee (Johnson-Anumonwo, 2019). The mentor and mentee ideally have a mutually constructed relationship where each can learn from one other.

Feminist and Black geographies are particularly situated to provide a framework for the analysis of mentoring due to its emphasis on the space of the body (Longhurst, 1995), informal and formal spaces (Williams and Crooks, 2008), and the construction of difference (Pratt and Hanson, 1994). Types and processes of mentorship have been critiqued and engaged with by feminist geographers of color over the last 20 years due to the whiteness of the discipline (Pulido 2002; Mahtani 2004) hoping to create more inclusive futures for women of color in geography. With the continuing neoliberalization of universities, the process of becoming a geographer continues to favor the traditional holder of the discipline; the white male (Hawkins, Manzi, \& Ojeda, 2013). Though the need has been identified for a more diverse mentors, the discipline has quite a long way to go to have sufficient representation (Nash, 2003; Falconer Al-Hindi, 2019; Johnson-Anumonwo, 2019). The colonial and imperial history of geography contributes to the involvement of particular knowledge being produced about race in the discipline; which furthers this same knowledge outside of the academy (Nash, 2003). The following sections will outline the two overarching realms of mentoring studied- formal and informal mentoring.

\subsubsection{Formal Mentoring}

Formal mentoring traditionally happens inorganically where a more senior individual in an organization provides support to a more junior individual (Eby and Lockwood, 2005). Formal mentoring in this sense can take place in the form of career, educational, and institutional mentoring. In disciplines such as geography who are inherently and predominately white (Pulido, 2002) formal mentoring can help those deemed 'other' to navigate spaces that were not created with them in mind.

In transforming feminist mentorship ethics, feminist geography strives to rework the production of performance practices with the white body in mind through critiquing racial injustice (Faria, Faola, Torres \& Henderson, 2019), and for embodying mentorship through a feminist lens (Moss, Debres, Cravey, Hyndman, Hirschboeck, \& Masucci, 1999). The production of performance practices illustrates embodied interactions that are held between mentor and mentee, which create complexity in the relationship due to performance potentially being misread (Adams-Hutchenson and Johnson, 2019). In her 2002 piece, Tricking the border guards: performing race, Mahtani utilizes Judith Butlers of gender performativity as a parallel to racial performativity. As Butler (1990) argues against the "fixity of gender identity ... [and] that 
gender is merely an elaborate, socially constructed fabrication" (p. 426). Though she agrees that gender is not binary, Mahtani critiques that Butler ignores race and space in her argument of performativity. In this sense, Butler does not engage with the connections between race, gender, and space in her model of performativity.

Often Black women are afflicted by tokenism as they are sustaining images of inclusion and solving problems when diversity issues emerge (Baldwin and Griffin, 2004). When women of color are put in these positions, they begin to obtain an outsider within identity that is situational and based on a history of injustice (Collins, 1996). This notion of identity politics has also been noted in Black geographies and runs parallel to broader geography and critical race scholarship including the formation of experience, and carceral power (McKittrick, 2006; Shabazz, 2015; Allen, Lawhon, and Pierce, 2018). Black women choose to engage in cohorts of others who provide advice, a sense of sisterhood, and connectedness; however, these networks are seldom found in the institutional structure of higher education (Patton and Harper, 2003). In the absence of formal mentoring networks professional organizations, churches, and symposia can act as an avenue of formal mentoring outside of the academy (Wilkerson, 1984). Another avenue in which Black women can obtain mentoring relationships are through Black sororities. If a Black sorority chapter exists in proximity to those seeking mentoring, there will be willing mentors to aid in navigating predominately white spaces with greater ease (Breakfield, 2010). Research regarding mentoring for Black women at PWI's is contradictory. Some report that Black students and white faculty struggle with cultivating strong mentoring relationships (Fleming, 1984; Mayo, Murguia and Padilla, 1995; Guiffrida and Douthit, 2010). However, there is also literature that supports the notion that Black students can have positive relationships with white mentors which allows for better experiences in PWI's (Alexander and Bodenhorn, 2012). Without formal mentorship in higher education and career avenues, change will be minimal (Mahtani, 2004). In instances where a mentor may not be available in career or educational institutions, Black sororities provide a formal mentoring network in lieu of an institutional mentor. This, however, does not present as a solution to the issue of a lack of mentors within an institution, but acts as a temporary remedy to the issue. Educational and career avenues are not the sole purpose of one's life and as such women may need to have a network of mentors, some of them being informal to aid in various aspects of life some to help with other aspects of life (Patton and Harper, 2003).

\subsubsection{Informal Mentoring}

Informal mentoring combines formal mentoring and friendship. Over time, mentor and mentee may form a friendship where there is mutual respect and no evaluation of performance. Peer-peer mentoring- a form of informal mentoring- in this sense can provide a home away from home in predominately white spaces. Women of color are often not able to access mentoring relationships with those inside of their institution and are forced to seek these relationships elsewhere in spaces such as sorority chapters and social clubs among other avenues (Harris, 1994; Bova, 2000). Mentoring relationships are invaluable for women of color and have been shown to mimic 
relationships of mother and daughter relationships. These relationships provide as Patton and Harper argue

"emotional support, learning survival skills such as how to maintain professionalism, dress properly, successfully navigate political environments and reject negative stereotypes that have been traditionally used to characterize African American Women" (2003, p. 72).

The emotional support received from peer-peer mentoring as Black women parallel that of the family system. Mentoring in this sense acts as a pseudo family for Black students whose dependence on their family relationships at home is needed while attending predominately white institutions (Alexander and Bodenhorn, 2015; Domingue, 2015).

This idea of emotional support and life skills through mentorship have been studied by feminist geographers. As such, Oberhauser and Caretta (2019) argue that mentoring is not only a space for professional advancement, but also for sharing work-life balance strategies. Recently, feminist geographers have engaged with the common themes of mentorship and the placelessness for minority students on college campuses (Webster \& Boyd, 2018; Faria, Faola, Henderson \& Torres, 2019; Webster \& Caretta, 2019). Much like Pope and Edwards (2016) highlight, Black female graduate students experience underrepresentation, and isolation in response to being viewed as a token. Their experiences are often overshadowed by pressures to conform, leading to "psychosocial trauma and internalized impostorship" (2016, p. 772). Once we acknowledge and validate the feelings of these students, as Falconer Al-Hindi notes, "[we can] commit to building mentoring relationships that are attentive to the fact that the neoliberal academy often places Black, other racialized, and Indigenous scholars within power geometries that differentially value their experiences, knowledge and voices" $(2019$, p. 3$)$ in order practice inclusion in mentoring relationships.

Because mentorship can be available at various scales, these relationships can often thrive beyond work productivity. Being cognizant of how institutions shape, and limit mentoring is of the utmost importance when practicing an anti-racist mentoring strategy (Laliberte and Bain, 2018). Mentors and mentees can create productive and positive spaces by instilling caring, responsible, and ethical practices into mentorship, helping to navigate predominately white spaces. (Gillen, Ziegler, Friess, \& Wasson, 2014; Ginn, 2014). In the same vein, some authors are not only focusing on the mentor-mentee relationship between emerging graduate students and early academics, but also focus on the emotional dimensions and friendships between one another (Pope and Edwards 2019). Women are much more than the sum of their academic or career achievements, and as such need to have a work-life balance. Mentors can model and promote friendship and work-life balance for their mentees (Patton and Harper, 2003). Because sorority membership is its own institution, if one is unable to procure an informal mentoring 
relationship in a woman's academic or career life, this type of relationship can be formed via informal mentorship within the sorority organization (Allison, 2016)

\section{Methodology}

This section outlines the research methodology including epistemology, positionality and reflexivity, and proposed methods for completing this research.

\subsection{Epistemology}

This project utilizes feminist epistemology. Feminist epistemology refutes that all knowledge is equal, but highlights that all knowledge is situated (Haraway, 1988). It asserts that the analysis of marginalized groups should not just be added into other theoretical frameworks, but that knowledge produced by marginalized groups itself is its own subject matter. It is important to note that situated knowledge is a social practice, not something that is tied directly to social positioning (Smith, 1990). Black feminist thought takes the notions of situated knowledge farther into standpoint theories which assert that social situatedness gives the subject a "privileged access to truth" which has since been rejected (Collins, 1997). Rather than standpoint theories providing access, they aim to open up dialogue between subjects who are differentially situated (Stoetzler and Yuval-Davis, 2002). The feminist standpoint itself was originally developed to oppose ideas that various social groups see the world in a certain way just because they inhabit a similar social location (Hartstock, 1997). For instance, because Black sorority women are members of a similar social location to that of their male counterparts it does not mean that they have the same experiences and produce the same types of knowledge. Hartstock also asserts that "standpoint is a project, not an inheritance; it is achieved, not given, and emphasizes the criteria for privileging some knowledges over others are not subject matters for epistemologies but are ethical and political" (Hartstock, 1997: 372). Communities themselves are constructed by and for various actors, often those with their own social positioning that is higher than the constructed community. Therefore, the creation of a 'standpoint' is constantly changing as such hierarchical relationships are broken down through collective resistance.

Feminist epistemology itself attempts to break down hierarchal relationships in research through the recognition of situated knowledge, which is grounded on and leads to positionality and reflexivity (Valentine, 2005). Because knowledge is situated and influenced by who creates it, feminist researchers must recognize their own position by being cognizant of how they see the world from various locations (Rose, 1997). No person is a singular, conscious entity without influence from their experiences and interactions with their environment. These multiple aspects of one's identity guide what types of research questions are asked and why (Alcoff, 1996).

The process by which this recognition occurs is called reflexivity. Being reflexive entails critically engaging with your own thoughts and inherent biases throughout the research process 
to challenge where they may come from and how they may influence the research relationship between the researcher and participant (Falconer Al-Hindi and Kawabata, 2005).

A Black feminist epistemology critiques positivistic thought at its core, rejecting that there is only one valid way of knowing that is disembodied from the researcher themselves. Black women in this regard, can produce credible research that contests the types of knowledge produced by the white male community. Positivistic thought requires African American women to objectify themselves, invalidate their emotions and histories, which Black feminist thought reflects Afrocentric value systems that existed prior to racism and oppression (Collins, 1989).

\subsection{Positionality}

Black feminist thought is not something that is the property of Black women but is something that should be completed with Black women central in its practice (Collins, 2006). Historically, Black feminist thought challenged the status quo; today its functions are more oppositional in nature. As Patricia Hill Collins notes in her 2016 piece,
"being oppositional means doing serious, diligent and thoughtful intellectual work that aims to dismantle unjust and political structures. For individual scholars from all backgrounds, this means looking beyond difficulties and ask[ing]: How does my work contribute to Black feminist thought's overall oppositional stance toward systemic, societal oppression? Just as we differ based on our social locations within intersecting power relations of race, gender, class, sexuality, age, ability, ethnicity, religion and nationality, our contributions will and should vary”. (2006, p. 134-135)

It would be impossible to conduct such a project without critically engaging with one's own motives and interests in the research. The following section expands on this and explains my positionality in choosing this topic.

Positionality is defined as the way in which our individual identities that we embody are positioned in relation to others outside of the self (Franks, 2002). My identity as a researcher, interests, and stakes could not possibly be encompassed in a few short paragraphs. My aim, as Richa Nagar illustrates, is a "speaking-with approach that treats both reflexivity and positionality as a process evolving over space and time; and crossing borders to build 'situated solidarities' rooted in our (multiple) contexts and place-based locations" (Nagar, 1985: 85). My interests and assumptions of why I embarked on this research topic have evolved throughout the research as I began to know more information.

Because I am not a woman of color, one might wonder why I have chosen this research topic in the first place. When we as women join Greek organizations, we look for a connection with one 
another, a sisterhood, and being of service to others. Because I have an insider perspective on the overall structure of Greek life, I was able to resonate and understand most things that participants shared about the way their organizations function. However, I am still an outsider in the fact that I am not a woman of color. Though you need not be a woman of color to be a member of the organization, I am also not a member of a Black sorority. I have completed this research to gain a better understanding of a different portion of Greek life that I did not have the privilege of participating in. It is not my intent to be a voice for these women; they have their own voices that do not need to be interpreted and regurgitated into an academic form by a white woman. Through my time in Greek life as an undergraduate student, I witnessed and acted as a bystander in many incidents in which I now know were both overt and covert acts of racism. It was not until I began to study geography that my entire outlook on the world changed, and I was able to critically see what kind of organization I was a part of, and what kinds of people I was choosing to surround myself with. I began to recognize acts of microaggressions and discrimination and began to feel uncomfortable which was ultimately one deciding factor in my decision to distance myself from Greek life. As bell hooks asserts, Black experiences are not reduced to their experiences of marginalization, but their experience as human beings (hooks, 1995). I hope to use this research to engage with other white women to help them understand the marginality of this topic as well as the historical context that runs deep through it. Engaging with unfamiliar organizations or people must be started with genuine curiosity. Often times, Black women are tasked with teaching others about their history, rather than voluntarily sharing their history. When asking participants how they would like the research to be disseminated, they expressed that it is up to white women to inquire with curiosity in order to appreciate the work and service that Black sororities have done in the community and model an example of true sisterhood.

It is also important for me to address that my research participants are not just a means to obtain information from but that they are human beings as well. I will attempt to create reciprocal relationships built on empathy and mutual respect (England, 1994). It is my goal to highlight the experiences of participants in a non-hierarchical way so that they can benefit from the research as well. These hierarchical boundaries were lessened because of my experiences with Greek organizations and the processes in which a woman will go through during her time as an undergraduate member of a sorority. I also got to know my participants on a personal level, treating them as equal human beings rather than test subjects even though there are conceivable differences in their experience from mine. Because of these insights, I decide to utilize a feminist epistemology to question the existing and emerging power dynamics in the interviews to make them as reciprocal and nonhierarchical as possible (see also: Cope, 2005). The power dynamics shifted throughout the research, at first, I was the interviewer inquiring about their experiences; while they are the experts in their own rights of their own experiences, I became the learner rather than the extractor. In the encounters with my participants I was the researcher rather than the researched, it would seem that I had more power in the relationship- attempting to extract information from the participant. However, in order to get the information, I needed and to create 
a relationship with participants I needed to get to know them and relate to them on a personal level.

\subsection{Methods}

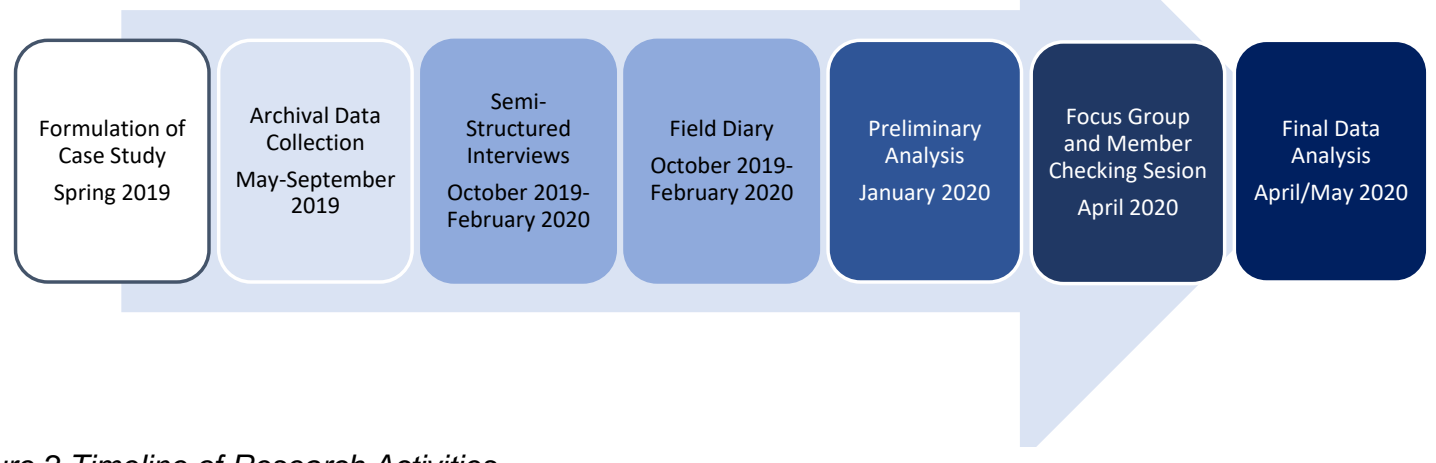

Figure 2 Timeline of Research Activities

To answer the research questions, building rapport with participants was necessary to obtain personal information from members of the organizations. The interview questions were about personal memories, stories and embodied experiences of being a woman of color in a predominately white area. Because of the personal and potentially sensitive nature of the information that I wanted to gather qualitative methods were most appropriate. Qualitative methods are in fact best suited because they allow the researcher to gain a deeper understanding of the material through direct and recurring dialogue with the participant. The mode of data gathering in qualitative research allows for a closer relationship rather than an uninvolved distant relationship constructed in other methods such as survey interviewing (McDowell, 1992). This section outlines the methods used through a case study approach, data gathered through archival research, semi-structured interviews and a field diary. The figure above (figure 2) shows the progression of the research and research methods on a continuous timeline starting in the spring semester of 2019 through April/May 2020.

\subsubsection{Case Study North Central West Virginia}

A case study in a geographical sense bounds the research to one locale that the researcher already has privileged access to (Clifford, Cope, Gillespie, and French, 2016). Case studies are used to gain a better understanding of a certain phenomenon, and to present representative insight to a larger picture (Yin, 2013). In this research, the case study is the North Central part of West Virginia, more specifically in the greater Morgantown area. I chose a case study methodology for because focusing on the University and surrounding area helps me to contextualize the research through generations of women in one location. As Gray notes, a case study allows for the synthesis of different perspectives that can create an intricate understanding of a particular 
context (2018). I chose this local area not only because of the ease of access and potential interviewees, but for the known lack of diversity in the state of West Virginia (Gaventa, 1980); and more specifically in the locale of the state's largest university, which is a PWI. During the first part of the research, I decided to expand the study area to about an hour radius of Morgantown, as one of the alumnae chapters encompasses south of Pittsburgh.

West Virginia University accepted few Black students prior to integration in 1954 in response to the Brown v. Board of Education court decision. However, the University was far ahead of its southern counterparts for the time. In 1938 the Supreme Court decision of State of Missouri Gaines v. Canada required universities to provide equal opportunity in graduate education for both Black and White students. WVU then became the first university in the United States to admit Black students to graduate and professional school based on this ruling (Lewis, 2013). Because of the marginal numbers of African Americans in Morgantown, examples of racism were overt in nature, but rarely documented. During and after the civil rights movement examples of racism in Morgantown were more covert in nature, with whites rejecting attempts towards affirmative action (Dominion Post, 1982).

Finding specific demographic data on faculty specifically has proven to be a challenge. Data gathered regarding diversity initiatives in the 1980's when the Center for Black Culture and Research was established, as well as diversity initiatives such as One WVU formed in 2008, show that although the University has appeared to make a concerted effort to establish networks for students of color, these spaces are still lacking. For instance, the number of courses offered in diversity or social justice have remained stagnant since the turn of the twenty-first century (West Virginia University, 2018). In 1985 and subsequent academic years, West Virginia University attempted to create recruitment initiatives to increase the Black student population. The enrollment goals were to reach 4.6\% African American students and 3.6\% African American faculty; these goals were not met and only reached 2.6 and $1.4 \%$ respectively (Lewis, 2013).

Data provided by the institution shows that the goals in 1985 have not yet been reached by the University. For 2018, Black full-time employees made up 3.1\% of the total full-time employee pool $(5,624)$, down $0.5 \%$ from the previous year in 2017 . This illustrates that even though distinctions are not made in faculty versus staff, there are only 174 full time Black employees at the University, while there were 857 Black undergraduate students comprising only $3.9 \%$ of the total undergraduate population (West Virginia University, 2018). In the following sections, I will outline the methods in the order in which they were used to analyze North Central West Virginia as the case study. 


\subsubsection{Archival Data Collection}

West Virginia University houses the West Virginia Regional History Center (WVRHC) on the $6^{\text {th }}$ floor of Downtown Wise Library. The center first opened in 1930 in order to preserve the papers of Senator Waitman T. Willey, one of the founding fathers of West Virginia. The center was officially established in 1933 to house public records and court records of early West Virginia. It was not until the 1950s that the archive began to include printed materials, audio, and other historical information regardless of their medium. The goal of the archives is to preserve and provide public access to information that shows the historical and cultural aspects of the central Appalachian region (West Virginia Regional History Center, 2019). The History Center is a special collection of the greater library structure. This means that the materials housed are rarer, in more varied formats, and more comprehensive than the traditional library's materials. There are three units in the History center: The Regional History Collection, the Rare Books Collection and other special collections. The West Virginia Collection has archives and manuscripts including material related to WVU offices, faculty, student organizations which contain about 4000 collections and 20,000 linear feet of shelf space (WVU Libraries, 2020).

Archives are, as Harvey and Davis Brown (1998) note, a space where various historic materials are stored, and cataloged by significance. Archival data provides a window to the past. However, historical sources only provide a partial picture of what life may have been like in a certain period, in a certain place. Especially when researching marginalized groups, it is important to note who is managing the archive, and the history of the archive itself to assess accuracy of information (Clifford et al., 2016). In geography, archive analysis is an underutilized method because it is thought of as a "solitary, self-directed undertaking" (Lorimer, 2018: 4). Not only is this method underutilized, it is becoming increasingly critiqued, with critical human geographers calling for more attention to the theories and methods used in historical geographies. Feminist historical geographers such as Moore argue that historical methods such as archive work offer "different possibilities for the recuperation of the agency and experience of the marginalized" (2018, p.2). As geographers continue to engage with more critical scholarship, the leading scholars in the field assert that historical data must be utilized in order to better understand research contexts by not only learning the historical context, but critically engaging with what is and what is not included in historical documentation (Arefin, Hennessy, McClintock, Mollett, and Van Sant, 2018). Use of archival materials can be participatory, allowing research participants to contribute to and use the archives in a politically active way (Moore, 2018). For example, when history is in the process of being reclaimed it can give research participants agency in creating an accurate narrative of their experiences rather than what is currently represented.

I completed archive data collection at the West Virginia Regional History Center housed in the West Virginia University Downtown Library during the summer of 2019. The sources I gathered 
included various newspaper articles from integration of the University in 1954 to 1996, personal artifacts and notes, and Greek life records consisting of incident reports. Archival search made emerge a lack of data on available housing for Black students during the Jim Crow era, housing discrimination, and demographic data for the Black student body overall, and more specifically in Greek life from integration to the present. After identifying gaps in the archive, it became apparent to me that the data found needed not only to be validated, but also triangulated with experiences that Black women currently have in higher education on campus.

I first browsed the online collections of the WVU Regional History Center to gain a broad knowledge of collections that African American women may have been mentioned in. Unfortunately, there was little to no information regarding African American women in the Morgantown area, let alone African American women in Black sororities. The archive held only one book that focused specifically on people of color in the county that houses Morgantown (Monongalia County) called Our Monongalia: A History of African Americans in Monongalia County, West Virginia (Rice, 1999). Because I had a primary topic that I was aiming to learn more about Greek life, I began to search for records that could possibly contain information regarding Greek life. There was more information to be found through this search, yielding I individual collections such as Greek life historical records, the Women's Centennial records, and the Victorine Louistall collection.

The Louistall collection was the main source of archival data utilized for this research. Victorine Louistall was the first African American woman to receive a graduate degree from WVU, and the first Black female to serve as a faculty member at WVU. The collection houses materials from various aspects of her life. The collection spans the years 1908-2006. Information from her life spans thirteen series including biographical materials, correspondence, photographs, newspaper clippings, Kelly Miller High School (where she attended), Alpha Kappa Alpha, Scrapbooks, Miscellaneous, awards, subjects, artwork, and artifacts (A\&M 3916). I visited the archive during the summer of 2019 over five different occasions to gather data. Later in the process while conducting interviews, I found myself needing higher quality pictures to bring to the interviews to use as boundary objects. When I went back to the archive, I found a scrapbook that was misplaced in the archive regarding Victorine's time in Alpha Kappa Alpha. The collection contents note that series six houses all of the materials containing information about Victorine's time in Alpha Kappa Alpha; however, there is also another series that describes other scrapbooks. These scrapbooks include "material regarding Louistall's professional and public activities (1953-1995)" (A\&M 3916). By chance I thought that it would be interesting to look at these scrapbooks on my last trip to the archive. Much to my surprise, the Alpha Kappa Alpha scrap book said to be housed in series six, was actually in series nine. If I would have never been simply curious, I never would have stumbled upon some of the most informative artifacts regarding Victorine's time in Alpha Kappa Alpha. I notified the archive clerk of the error in the organization of the archive, and it was remediated; however, I wondered if there were any other 
errors in the organization of the archive and wondered if there may be other information regarding Black sororities at WVU that were simply misplaced or cataloged wrong.

From all material gained in the archive through the Louistall collection and university records, I constructed a timeline of women's and more specifically Black women's history and acts of injustice at West Virginia University from 1938 onward (see below).

\section{Constructed Timeline}

1897: First time that women organized on their own behalf at the university (Women's League of WVU) Housing problems plagued WVU especially for women since the beginning of the university.

1938: Supreme court decided that African Americans must have equal opportunity in graduate education, WVU became the first college in the US to admit black students as a result of this ruling.

1940: Geraldine Vickers enrolls at WVU

1941: Victorine Louistall comes to Morgantown Kenneth James is the first African American to receive a MEd degree from WVU

1942: William O. Armstrong becomes the first black male to get a master's degree at WVU (fully received from WVU).

1944: Geraldine Vickers Harrison graduates from WVU graduate school

1945: Victorine Louistall becomes the first black woman to get a graduate degree at WVU.

1949: Glenda Edwards Waters gets M.Ed. degree, was the first black person appointed to teach in WWII, winner of the Alpha Kappa Alpha outstanding alumnus award, and the Morgantown bicentennial award.

First Black graduate from the school of Law.

1951: First Black Graduate student allowed in dorms

1954: First black student (Hodge) to earn an undergraduate degree from WVU.

Brown v. Board of Education- Integration

John Ruben Sheeler first African American to receive a PhD from WVU (History)

1955: Alpha Kappa Alpha regional conference in Pittsburgh

1957: Annette Chandler-Broome graduates as the first undergraduate woman to get a degree from WVU

1962: Picture of Kappa Alpha Psi gathering

1965: First Black medical school grad

1966: Victorine Louistall becomes the first Black professor at WVU

First Black graduate of the nursing school

1967: Correspondence about not letting another black fraternity on campus because of 'reverse racism' Article on "WVU frats bar negroes"

1967-68: IFC report "someday we will have to face the issue of Negroes in frats"

1968: Social justice statement at the university

Gibson v. Florida investigation committee supreme court ruling

1969: The greek letter "The man behind the Blacks- Nelson Bickley advisor to black and international students.

Spotlight on Black FB player Oscar Patrick, Black Miss WVU Deborah Ridley

AKA Convention and Black Unity orgs pics from archives 
1970: Feb 27, 1970 AKA introduced to campus.

April 17: four women pledge AKA

Gamma Chi Omega alumni chapter article on the newly formed chapter

1972: Black greek orgs on campus: AKA, Kappa Alpha Psi \& Alpha Phi Alpha

1973: April 10 Omega Psi Phi introduced to campus

1978: Victorine Louistall becomes professor emerita

1978-1979 First Black Awareness Week at WVU Put on by the Black Unity Organization

1980: First black graduate of the mineral and energy resources college.

"Racism: a new meaning for the 80s article on Affirmative Action

1981: Victorine Louistall appointed first Black women to the president's advisory board.

1985: First woman Rhodes Scholar is also the first Black woman to become a Rhodes Scholar.

1986: First Black homecoming queen

1987: WVU Center for Black Culture and Research established

1988: Cleckly article on hostile racial climate on campus. At the time there are 18/1374 faculty, 9/143 administrators, 88/2757 staff, and 461/17,300 students who are Black.

1989: First Black Truman and Presidential Scholars.

White supremacy group cards circulated

1991: Article on Black reeks notes that one frat has a house, Phi Beta Sigma

1992: Center for Black culture and research renovation and dedication (500 black students, 15 faculty \& administrators \& 100 classified staff noted at this time.

1986-1995: Dominion Post investigation of racism on campus

2002: KKK fliers distributed throughout Morgantown

2007: "WVU has a diversity problem" article $7.5 \%$ of undergrads are of minority groups

2008: "One WVU campaign" article on 'self-segregation' and lack of diversity

Diversity Week Launched

2009: Blackface incident with girls' soccer team for Halloween costume

Article debating the future of black greek orgs on campus 'do we really still need them?"

2010: Zeta Phi Beta and other minority organizations hold a minority panel

'Racial divide' comments noted in Charleston Gazette by a WVU Student

810 total Black students at the time

2011: The rack student pantry is raided, and racial slurs are left behind

2015: Student profiled by the cops in a misunderstanding over a parking ticket

NAACP student chapter has more diversity concerns article

2016-2017: Campus read Hidden Figures

2017: CBC director responds to the 'pendulum' of race relations in a post-Obama era.

2019: Alpha Phi Sorority investigated for black face lynching baby doll incident

NAACP calls for further investigation after sororities 'mistake' is not 'one intended of

Blackface'

This timeline, while interesting and important to understanding the climate of the greater Morgantown area did not play as much a role in the research as I had hoped that it would at the beginning. As the research questions shifted and I began to look more so at alumni membership rather than undergraduate membership, the focus on the university itself waned. However, the 
experiences that participants had while at the university or their respective universities correlated with the timeline. Experiences elicited by the participants confirmed that racial tensions in the area have always been in flux; because the university is such a prevalent institution in the general greater Morgantown area, it's legacy of non-inclusivity and racism pervades the general area as well.

As the timeline shows, people of color have faced and continue to face a lack of representation in faculty, racialized student conduct violations, and racial discrimination in Greek Life. The entire WVRHC archive was incomplete and unsatisfactory: more materials would have provided insights into the lives of Black women in the past (see examples below). In order to gain a better understanding of Black Sorority members lived experiences of being a woman of color in West Virginia, I decided to complement data collecting through semi-structured interviews. Objects and pictures found in the archive were used as boundary objects to facilitate dialogue in interviews, bridging the gap between historical and present times. In the following section, I will explain the second method of data collection due to the fact that the information found was unsatisfactory, thus the need for collecting various forms of data.

\subsubsection{Semi Structured Interviews}

Semi-structured interviews are verbal exchanges between an interviewer and a participant where the interviewer tries to obtain information by asking a pre-determined set of questions (Longhurst, 2016). Interview data was gathered from December 2019 to March 2020. Six semistructured interviews helped to fill gaps in archival data because the archives tend to be factual and descriptive rather than embodied (Clifford and Cope et al., 2016). The number of active alumni women living in Morgantown willing to speak with me was less than initially anticipated. Many of the women who met the study criteria were at transitional points in their personal lives and did not have time to meet with me. Older members of the organizations (above 60) were also hesitant to speak with me; I have attributed this to the fact that they view their experiences as private and I was not able to build that trusting relationship through the snowball sampling. There are currently two active Black sororities on the West Virginia University campus: Delta Sigma Theta and Zeta Phi Beta. Interviews allowed me to ask those who are members of Black sororities about their experiences, rather than focusing solely on objective documentation through archive and literature.

The interview guide consisted of 17 open-ended questions that prompted the interviewee to speak about their lived experiences as a woman of color in an alumnae chapter of a Black sorority. Included in the interview guide were a set of boundary objects that were collected in the archive (see below) 


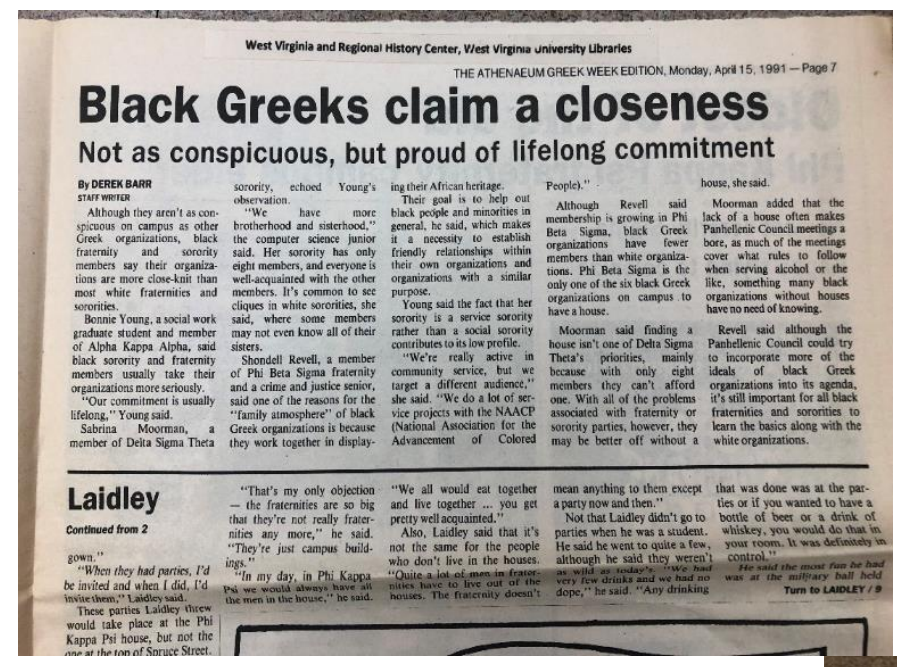

Figure 3 Newspaper article from 1991 outlining the differences between Black and White Greek Life- Also used as boundary object

Figure 4 Napkins and place card from a symposium on intercultural relationships hosted by Alpha Kappa Alpha and in attendance Zeta Phi Beta and Phi Beta Sigma

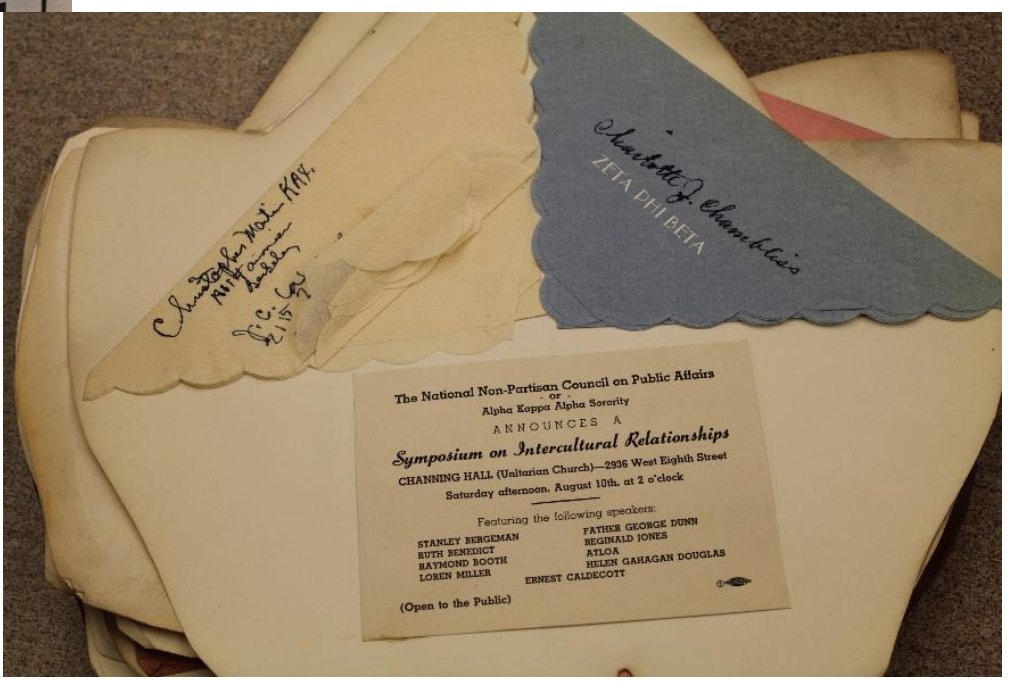

Figure 5 Alpha Kappa Alpha regional conference 1955 (Also used as boundary object)

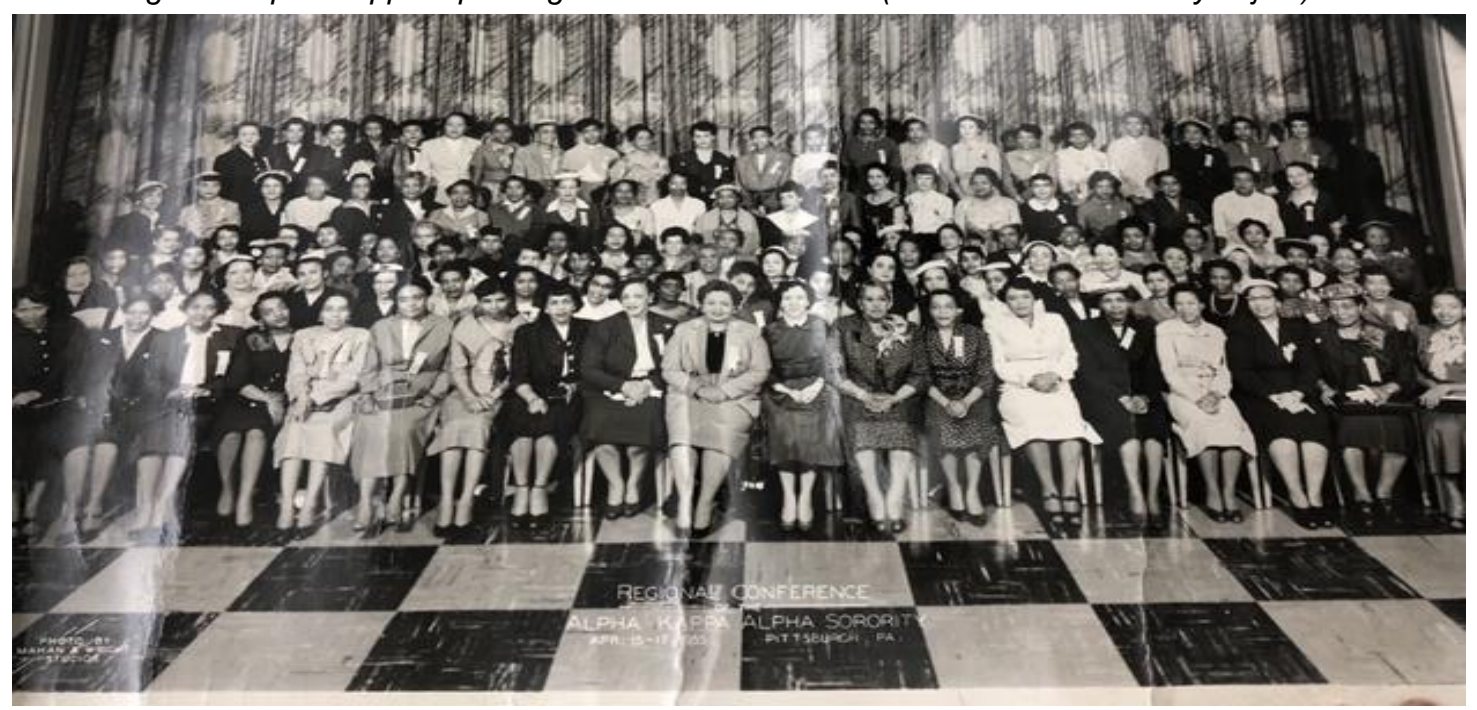




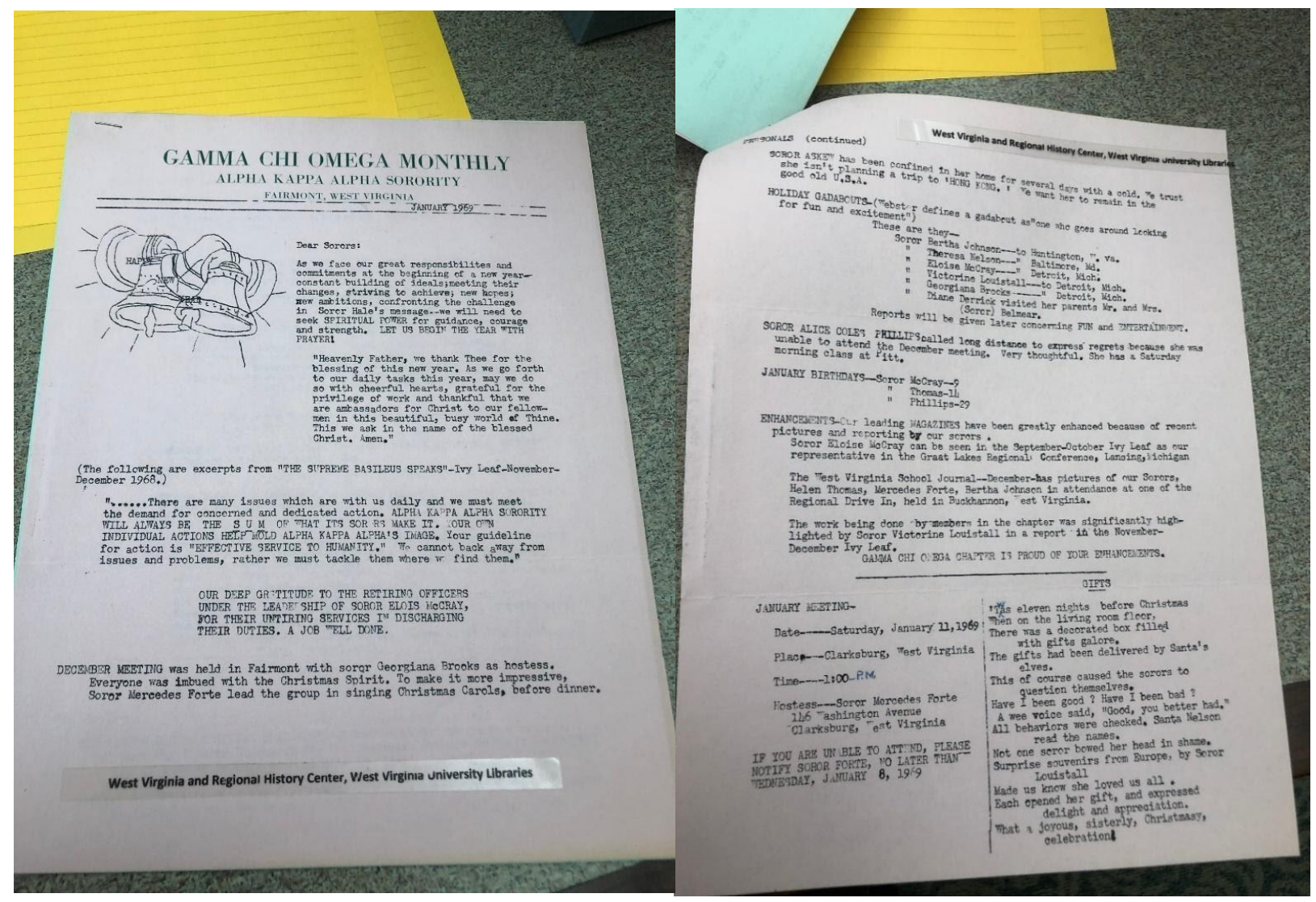

Figure 6 Alpha Kappa Alpha Sorority meeting agenda from January 1959 which entails the agenda for the meeting as well as future and current projects

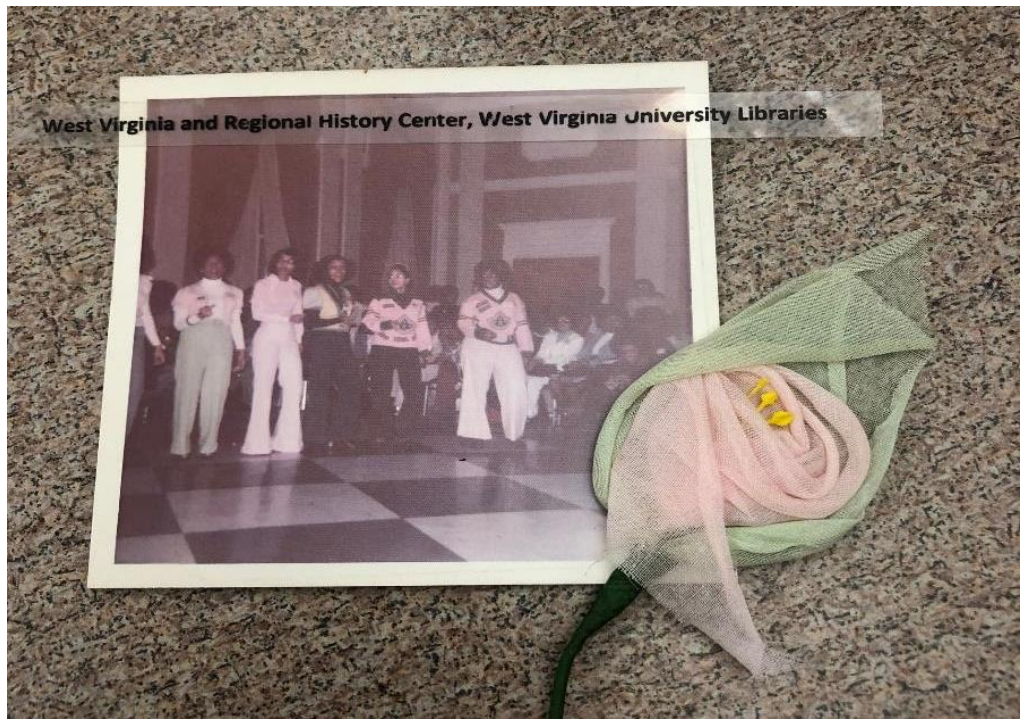

Figure 7 Picture of Alpha Kappa Alpha women at a social gathering in the 1970 's, and a routineer from the event 


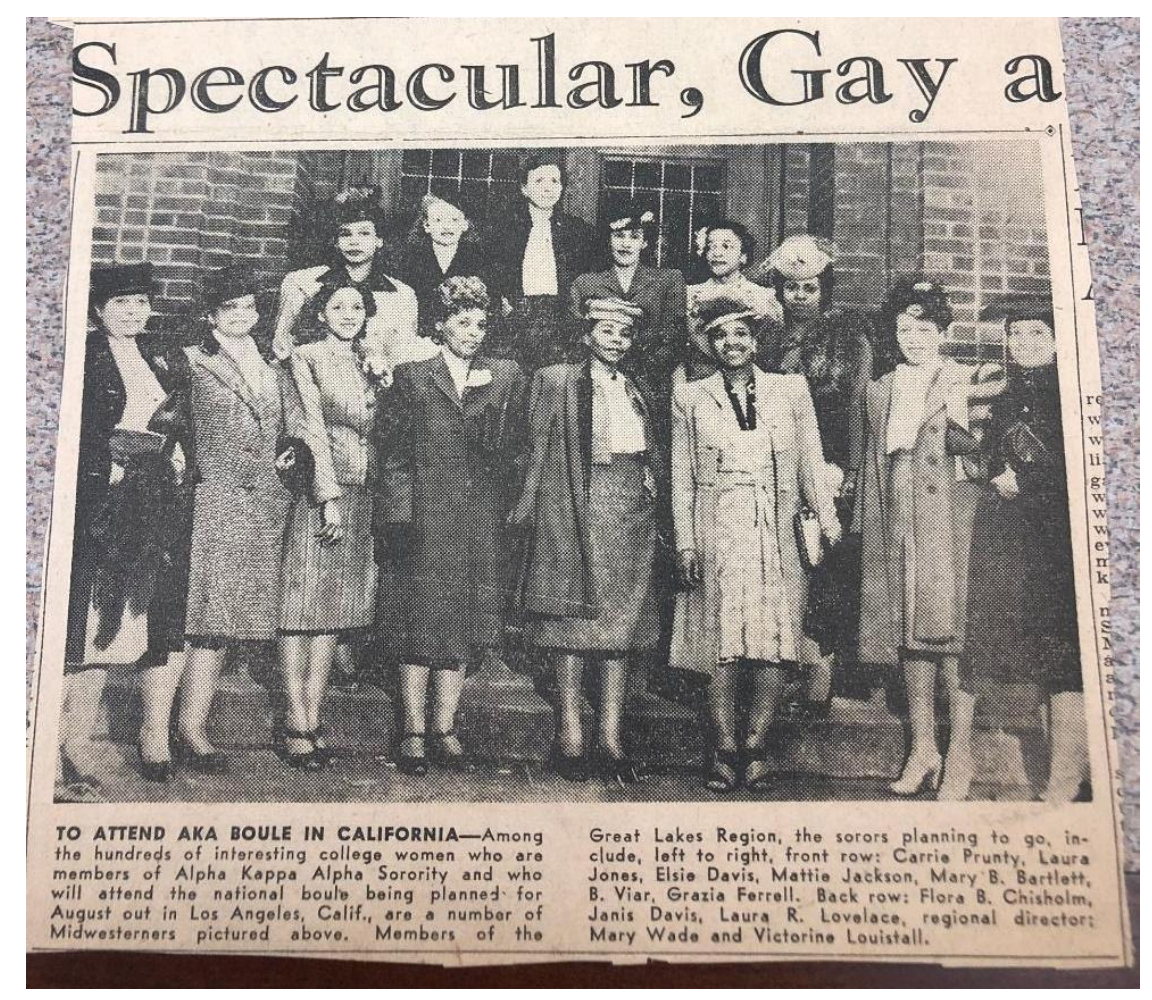

Figure 8 Alpha Kappa Alpha Members travel to California from Pittsburgh to Boule their international conference

In order to connect the archive research to the data collection, sharing some of the materials gathered as boundary objects allowed for a deeper conversation. Boundary objects are artifacts or pictures that can facilitate conversation and enhance the spaces of exchange between the researcher and the participants; the researcher can present what has been found to date, and the participant can explain what it means to them, and how their experiences corroborate or differ from what is presented (Lagesen, 2010). While using the boundary objects elicited responses for some participants, they did not elicit substantial reactions from others. Because the artifacts found in the archive were only representative of Alpha Kappa Alpha, those who were members of Delta Sigma Theta or Zeta Phi Beta did not elicit the same reactions.

\begin{tabular}{|c|c|c|}
\hline Interviewee & Organization & Reaction \\
\hline 1 & Alpha Kappa Alpha & Visceral, Emotional Reaction \\
\hline 2 & Delta Sigma Theta & Intrigued \\
\hline 3 & Zeta Phi Beta & Captivated not Emotional \\
\hline 4 & Delta Sigma Theta & Engaged not Emotional \\
\hline 5 & Zeta Phi Beta & Fascinated not Emotional \\
\hline 6 & Zeta Phi Beta & Intrigued not Emotional \\
\hline
\end{tabular}


All of the participants were interested in seeing the pictures of the artifacts that I had gathered, and showed a general sense of agreement that overall, they were representative of their experience as a NPHC woman. However, only the member of Alpha Kappa Alpha had a visceral reaction. Were there to have been a more comprehensive historical account of the other two organizations in the archive, these methods may have guided the interviews in the intended way. Though the interviews were not so much guided by the boundary objects, this in itself is another argument for the inadequacy of the historical account housed in the archive.

Because of the potential for these pictures and interview questions to elicit visceral reactions and responses, while drafting the interview guide, I aimed to be sensitive to the women's emotions. In order to mitigate the potential sensitivity of some of these issues, I provided referral information for counseling services if sensitive topics bring up emotions, they make like to explore further with a therapist.

Given that the chosen case study is a predominately white institute (PWI) the limited number of potential interviewees available, the breadth of interview questions and the variety of organizations sampled, I trust that semi-structured interviews allowed me to obtain representative individuals stories. Most importantly, these participants, through the semi-structured interviews, could make sense of their own lives rather than aiming for representation of an entire group (Clifford et al., 2016). Semi-structured interviews data allow me also to validate data previously gathered at the archives, to verify whether the experiences I grasped through documents are embodied in current Black female students' everyday lives in the present. In the next section, I will provide an overview of the type of sampling procedures utilized.

\subsection{Sampling}

I used two sampling methods: theoretical and snowball sampling. Overall, theoretical sampling best fits due to the ability of the researcher to set tentative targets, which can be revised, and to be able to make informed decisions of when to stop sampling (Mason, 2017). Accordingly, in order to participate in the study, an interviewee had to be an alumni member of a Black sorority in the greater Morgantown area. I was able to use snowball sampling which were shared with me during my time as a Diversity Ambassador for the Division of Diversity, Equity and Inclusion at WVU.

Snowball sampling is suited for this project because of the sensitive nature of the topic, and insider knowledge required from organizations in which I am an outsider to. Through these gatekeepers, I will be able to identify others who may have beneficial insights for the research (Gray, 2018). The goal is for this sample size to reach data saturation. Though different specific experiences were shared by all of the women interviewed, they all expressed similar answers to 
each question asked. A prevalence of similar responses indicates saturation, the data collected will be reliable and new interviews or focus groups do not yield new knowledge (Gray, 2018) which was reached through six interviews. While conducting interviews, I kept a diary of my initial impressions and thoughts prior to, during, and after completing the interviews. In the following section I will explain further the efficacy of keeping a field diary.

\subsection{Field Diary}

A field diary is a form of participant observation that is a defining characteristic of ethnographic research which highlights "how bodies interact, meld, and constitute social spaces, and thereby create inclusions and exclusions" (Watson and Till, 2018: 4). The field diary is a record of my initial observations, most impactful impressions, and other observations that may not be transferable through only audio recording of the interview. These rich observations allowed me to immerse myself within the research. I completed the diary directly after each interview to ensure that my impressions were recorded as soon as possible after the interview as to not miss out on key observations . The field diary acted also as a reflexive practice to adhere to my commitment to a feminist methodology. Reflexivity is defined as a process of self-critique pushing back on implicit biases that may arise during the research process due to your own positionality and epistemology (Rose 1993, Kobayashi, 1994). The process of creating the field diary aided me in being reflexive, because it recorded my initial impressions regardless of the relevance or accuracy to what was shared with me. Being able to recognize implicit biases, particular feelings or impressions of the interviews directly after the interview allowed such impressions to be preserved and analyzed later.

\subsection{Member Checking}

Validation in qualitative research can take on many forms. During interviews, validation happens through communicative validation i.e. by prompting interviewees to expand on responses, ensuring the time spent interviewing is sufficient, and building rapport and trust, allowing the informant to feel comfortable giving authentic answers (Gray, 2018). Further, transactional validity can be achieved when the researcher, the participants and the data can interact in ways to revisit facts, feelings, experiences and beliefs that are collected and interpreted (Cho and Trent, 2006). Such a process of achieving validity in qualitative research involves employing different methods such as data triangulation, member checking, and self-reflection. Data triangulation is commonly used when employing various methods in order to cross-reference that the different methods used yield comparable results (Clifford, Cope, Gillespie, \& French, 2016). Member checking is a reflexive process that can help to also triangulate data by presenting preliminary findings to participants in the study (Caretta, 2015). I triangulated the interview data with my field diary as well as transcription confirmation and a member checking session that was held with five out of the six study participants on April $22^{\text {nd }}, 2020$. Interviews were transcribed by me 
and then sent back to the participant to make sure that what was transcribed was a correct account of their experiences. The session served as a means of triangulation and allowed participants to network with likeminded individuals. Once the member checking session and all interviews were complete, data analysis began.

\subsection{Data Analysis}

After each interview I transcribed and coded each interview for re-occurring words and phrases that were prevalent in each interview. I then viewed the highlighted words and phrases and began to group together common themes. I first compiled a preliminary analysis of both the archive and interview data integrated into the common themes. The preliminary analysis was checked by my advisor and laboratory colleague in order to ensure intersubjective reliability. Intersubjectivity operates on the notion that each individual has their own epistemology and set of experiences, a lens in which they can look at the data in order to bring unique interpretations that the primary researcher otherwise would not have seen (Gillespie and Cornish, 2010). I then sent the preliminary analysis to participants so that they had the chance to review my interpretation and critique or validate the analysis.

Because I had both interview data and archival data, I needed to integrate the information gathered through both mediums. Archival data was first compiled and put into a timeline (see appendix). Data (pictures, memos, memorabilia) was also compiled into the following themes: individual, social, organizational structure, travel/conferences. Interviews were recorded and transcribed. As I read each interview several times, I highlighted words and phrases that stuck out or were repeated, as well as impactful quotes. Once this was completed with each interview, the words and phrases highlighted were compiled into the following categories: deeper connection, legacy, NPHC unity, and mentorship. Once I had compiled the categories I matched up the archival materials to the text in the categories. Upon completing this, it was very apparent that the archival material was not enough. There were no documents or artifacts to support the themes of sense of belonging or identity.

\section{Results}

The following section incorporates archival data, interview data, field diary, and focus group data. I am presenting the data gathered according to the three research questions about mentorship, sense of belonging, and identity formation. All participants spoke to their experiences with various forms of mentorship, NPHC unity, and how sorority membership has impacted their lives in positive ways. Data selected below best represents and conveys to the research questions and is organized according to the definitions presented in the conceptual framework of formal mentoring and informal mentoring. 


\subsection{Formal Mentoring}

Formal mentoring in Black sororities takes form through educational and career mentoring. Types of formal mentoring for women of color specifically have changed rather quickly over time. Previously the majority of Black women held roles in care positions such as teachers, secretaries, and social workers (Interviewee \#3, February 2020). The majority of participants were first generation college students. Each of the women interviewed reflected on positive experiences that they had with either an educational or career mentor.

\subsubsection{Sense of Belonging}

After graduation from college or university, many women reported having a transitional period. Women may move, gain new employment, start families, or work towards other personal milestones. In these times of transition, interviewees reported looking forward to joining alumnae chapters for support networks that allows them to feel a part of something bigger than themselves throughout a trying time. These mentoring relationships range from support while traveling to offering temporary housing for Sorors. Sorors will offer what others may call grandiose gestures, while membership has taught them to perform such tasks without question, even if they do not know the Soror personally. Each Soror has gone through the same set of practices and holds the same values as one other; the foundation of the organization also serves as the foundation for a personal relationship. The following quote expresses the organizational relationship provided by the Sorority.

"It's those things are protocol that as you bring in new initiates you keep them under your wing, to try and show them like if there is a Soror who announces "I'm coming to your city/town' it's customary that you would offer to take her to dinner, or for her to stay with you or if there was time for you to meet up, or maybe you would send a basket to her hotel room, things like that. That is expected. It brings you in the mindset of camaraderie between college women and between college trained women, and women in general." $A K A$

Women reported that when first coming into the organization, they are assigned a mentor who makes them feel welcomed from day one. Interviewees stressed the importance of an online network in gaining support while travelling or moving to a new city. A Soror can reach out to Facebook and other networking platforms to allow the larger group to know where they are travelling. There is a sense of comfort and safety for the women knowing that no matter where they go, they will always have a family member of sorts there waiting for them. Those who have had the opportunity to be mentors in the organization spoke to how enriching of an experience it was to aid other women of color in joining the organization. One participant spoke about an experience that she had in mentoring someone in their journey to become a member of the organization: 
"For example, this week I wrote a letter of recommendation for someone to be considered for membership, she's in Hawaii so she's trying to get into the Hawaii chapter. I'm already thinking oh if she makes it, I'm going to fly to Hawaii to stand and pin her. That's something I would do. So, I would travel anywhere." - [Interviewee \#3 February 2020]

"I did not have a job I didn't have a place to stay. I just packed all of my things in my car and drove 13 and a half hours from Kansas City to here and didn't have a place to live or anything. So, I got here, and still had all of my stuff in my car and she took me to dinner, and we started talking. "you'll stay with me ... you can stay with me until you find a job and a place"... I told her, I don't even have a job yet and I'm not sure how long this is going to take. But it didn't matter. I stayed with her for over a month and a half and until I found a place and moved into my place. I tried to pay her; she wouldn't take anything. My parents ... my dad came up here to visit and he tried to pay her, and she wouldn't take it. She allowed him to take her to dinner, like we all went to dinner together, but she would not accept anything, and she just said, "that's what sorority members do". [Interviewee \#1 January 2020]

In this instance above, the interviewee's basic needs were taken care of by a Soror who had never met her before. While this was the most clear-cut example shared with me during the interview process; each of the women relayed feeling welcomed into a new place by Sorors that they did not know.

This sense of belonging is also evident in the archives through documentation from previous gatherings of Alpha Kappa Alpha. While the digital age has made mentoring networks easier, these have existed since the beginnings of the organization. The following picture found in the archive illustrates this network in 1946. AKA women from various cities in north central West Virginia gather for a meeting. The second pictures illustrate a typical agenda for a monthly meeting which highlights members who were published in the national magazine, and in the West Virginia School Journal as well as upcoming birthdays and events. Archive minute meetings revealed that members in this chapter hailed from West Virginia, Michigan, Maryland and Pennsylvania. The document also showed that even though the internet had not been invented yet, those who were unable to attend the meeting made long distance calls to be included in the meeting. This is shown in the following photos as well as updates on sick members who could not attend the monthly meeting. This example of a meeting agenda shows the commitment members make to being present and being present to each other in times of need. 


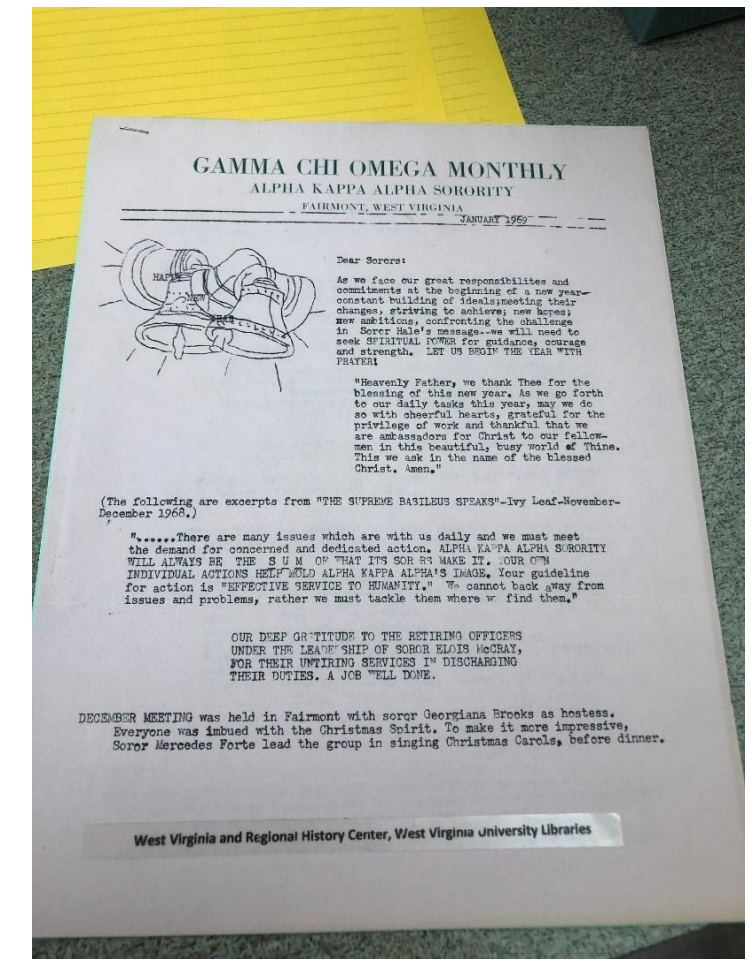

Figure 9 Alpha Kappa Alpha Meeting Minutes Page 1

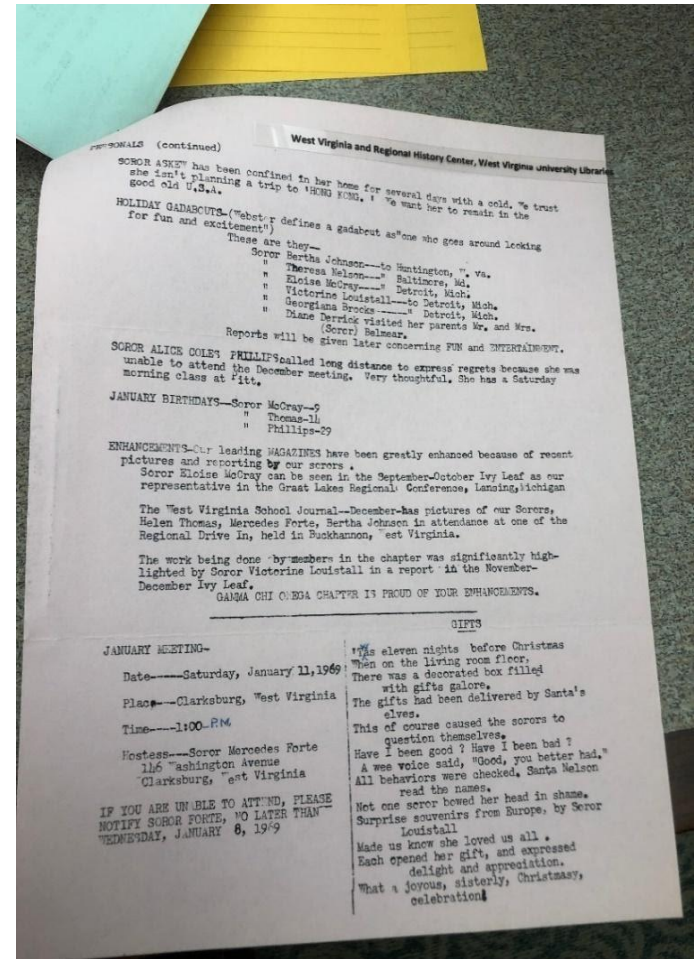

Figure 10 Alpha Kappa Alpha Meeting Minutes Page 2

Interviewees shared that meeting agendas today are received electronically, but these examples show not only chapter business but highlight the social aspects and well-being of its members. The idea that each Soror in a chapter knows each other and knows each other on a deeper level contributes to a sense of belonging to a group larger than oneself. A sense of belonging in a sorority with experiences such as those mentioned above contribute to a sense of belonging in a woman's physical and personal space. Formal networks gained through membership help to aid in this sense of belonging and hence the woman's identity

\subsubsection{Identity}

Women not only experience these formal networks through the organization at a personal level, but also at other levels. The study participants really stressed the importance of networking because each of them had been to a local, regional, and national conference for each of their organizations. Gathering for the large conferences allowed the participants to meet with local and international sisters who have different perspectives but similar views and values regarding the intricacies of the organization and the way in which they live their lives through the organization. At the national conference's women are able to network with each other, complete professional development sessions, and bond through completing service projects. In the archive there was some evidence of networking and artifacts from different conferences as can be seen below. 
This artifact (figure 6) shows that even the theme of the conference was regarding networking and building peace in the world. Nationally, there are two mentoring networks, one through each individual chapter, and also one in the broader NPHC community. This network extends beyond the individual chapter, but to regions and other NPHC chapters across the US. While mentoring within the organization is important in instilling values, much of the relationship surrounds daily life tasks and transitions. This network is not only occupying a physical space through conferences, meetings, and physical interaction but also a digital space.

As shown by the artifact beside, peace building and inclusion is something that each of the organizations hold as an organizational value. Though such artifacts in the archive can contribute to preserving

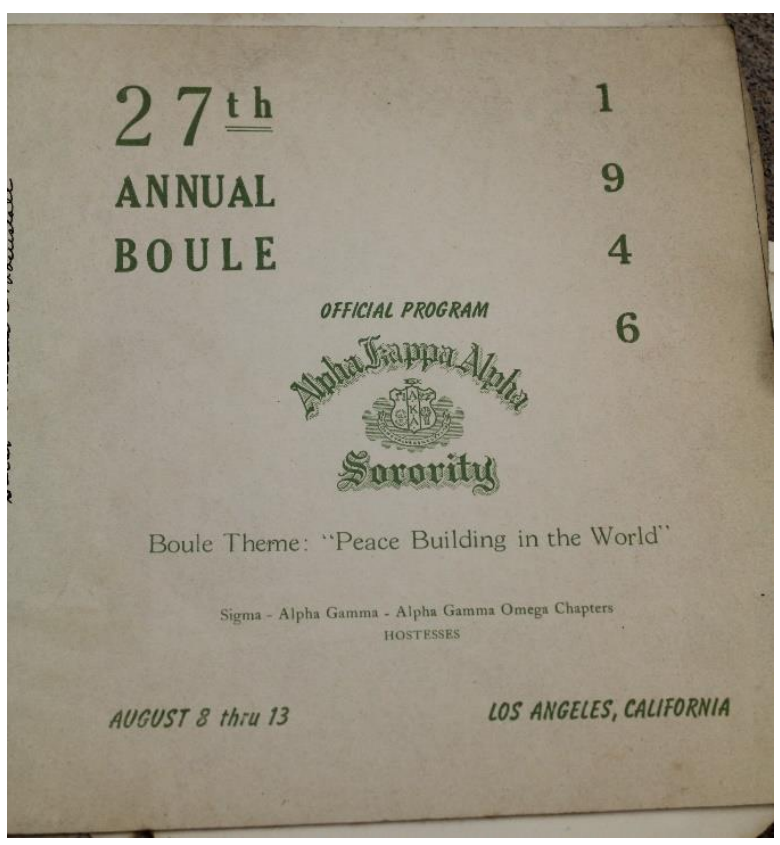

Figure 11: Program from the Alpha Kappa Alpha Boule in 1946 held in Los Angeles California with the theme was "Peace Building in the World such instances of formal forms of mentorship, not all archives and universities are equally adamant about preserving black history. Because the archive did not sufficiently document the inception of the NPHC organizations or what they have done for the community since the 1960 's, I was hoping to gain a better understanding of the history via research participants. Unfortunately, this was not the case due in part to interviewees not entering a chapter as an undergraduate specifically in West Virginia. As one interviewee recognized, it is not surprising that there was a lack of information in the archive at the university as shown below:

"So you want to know about the history of us in this community, unfortunately this predominantly white institution is not going to have it for you, but who will have it are all of your black churches in this area because we make sure that we keep up with our own history. It's sad and unfortunate that WVU doesn't do a very good job or even try to go back and say what was the history. But let's be real this institution was founded for white cis heterosexual Christian men. So they do a really good job of making sure that legacy is preserved, and we can't... our organizations don't fault them for that because at the end of the day we tell people that we'd rather tell our own story than have someone else control the narrative about what we are and who we were." - [Interviewee \#2 February 2020] 
Here we see the ripple effects that racism and exclusion has had on educational communities. Though many would believe that the university today is inclusive, it is not documented as to how efforts to increase diversity have happened. Especially for a large university in a state that is predominately white, it can be difficult to admit the wrongdoings of the past. The institution itself was founded only for men in a time where African Americans were not thought of as citizens, and is still ran by predominately white Christian men, the same demographic that it was created for. On the other hand, as stated above members of Black sorority members do not want this history to be rectified if it is going to be rectified by those whose predecessors were those committed the acts of exclusion. One goal of Black sororities is in fact to help spread awareness of Black history, and as such they would like to archive their history in ways that they would want it to be preserved.

University records showed that Black students were not admitted into the university until 1938 when graduate programs began to accept people of color. However, there is ample evidence of families of color in the greater Morgantown area through school records found in the archive. Victorine Louistall did not become an AKA during her time at WVU, and like many others who had attended HBCU's did not stop their philanthropic efforts to the communities in which they lived while there were no active undergraduate chapters. Programming offered by the NPHC organizations such as mentoring programs, financial and educational assistance benefitted not only Black but poor white communities as well. Each organization has their own national philanthropic and service organization affiliates and missions that change with the changing social and political climate. Local chapters also will tailor their service efforts to serve the communities in which they live, in whatever way possible as the following quote illustrates:

"We come together just like the 2020 census is coming up and it's important and imperative to all of us. So, you'll see all of the greek orgs including the masonic organizations all working together because West Virginia cannot afford to lose a congressional seat". DST 1

This quote shows not only the cultural significance but also the meaning of keeping an engagement with activism and togetherness within the community to make sure things are done in an equitable way. Interviewees spoke about the impact that these organizations had on their communities not only within predominately white spaces, but in local Black communities in West Virginia, particularly in the southern portion of the state. They also reported that in predominately Black communities it is typical for church leaders, teachers, and other essential community role models to also be members of NPHC organizations that not only help their communities through programming, but through assisting in helping to form the neighborhood identity. 


\subsection{Informal Mentoring}

\subsubsection{Sense of Belonging}

One common theme throughout the interviews and archival data collection was the impact that predominately white spaces have on women of color's sense of belonging. Archival data on these organizations was scarce not only for the first organization introduced to campus (Alpha Kappa Alpha), but also the histories of the two other organizations that have been on campus (Delta Sigma Theta and Zeta Phi Beta). The only evidence found in the archive of the two organizations were in the broader regional history center in the university year books- with no mention of alumni involvement. This would lead one to believe that Black sororities are similar to that of their traditional counterparts where women spend four years rather than their lifetimes serving as members of their respective organization. Yet, as I will highlight with the following examples, this assumption is the exact opposite of what is needed to preserve the history and legacy of chapters who have served the greater Morgantown area over time.

Some of the participants struggled with choosing just one person who they viewed as a mentor or inspiration, as there are so many women in their sorority life that are contributing to the organization and society. Because this type of mentorship is so intimate, it was not possible to capture the magnitude and intricacy of these relationships through archival materials.

"I think for me noble women in Delta who stand out are women who are really upholding the mission of our organization. Regardless of what happens in life are still remaining financial or still remaining on the battlefield and fighting against social injustice, policies and practices but I think I can find something in every Delta woman that would inspire me to be a better Delta woman or a better woman each and every day." [Interviewee \#4 February 2020]

"I remember the deltas in charge who were very politically active, and I remember me as a freshman looking in awe at them and wanting to be like that. Wanting to be as articulate as they were, as passionate and knowledgeable as they were and just sitting in awe and feeling good about wanting to be a Delta. I remember I found Mary Johnson in terms of our bodies we were similar. She was tall, she was thick, and I identified with her. I remembered for a very long time when I came, I met some deltas that I didn't like and I remember that it was good to have in mind the ones that I really identified with because they could erase the ones that I didn't identify with." - [Interviewee \#3 February 2020]

In the first quote the participant notes the unyielding commitment to the organization regardless of life events. For her, it was difficult to think of one person who was most inspiring, because she found that each and every one of her sisters had something in their character that looked up 
to and embody. The last quote spoke to the appreciation for peers who turned into sisters not only on an emotional level, but on a physical level. This participant recognized the physical similarities that she shared with her peer, which in turn, allowed her to feel welcomed and accepted. This comfortability became deeper through social justice and political action which contributes to the peer-peer relationships in which women in these organizations aspire to be a part of. The missions of these organizations would not be preserved or could function without highly dedicated individuals who share personal, professional and family experiences with each other, helping to form the identity of each and every member.

The following quote conveys the embodied experience that the interviewee had while joining the sorority. The most intimate scale in which the data represents is the scale of the body. To be able to physically identify with someone helps to create a sense of belonging in a space. When one knows that there are others who look like them, they feel at home. Every interviewee shared personal stories regarding how the sorority has contributed to their home, school, work and social life, clarifying how their identity had been shaped by these experiences. The importance of mentors at the peer level shows just how deep the connections are; each participant reported that there is absolutely no distinction between biological and greek family. The greek family extends to not only members of their respective organizations, but peers in other organizations. Especially in predominately white environments, peer-peer relationships predicated on the values of organizations which are very similar help women of color band together and act as each other's main support systems. This banding together and sense of belonging can aid in the identity formation of an individual.

\subsubsection{Identity}

Identity formation on the personal level is directly impacted by the psychosocial mentoring that is received during membership in a Black sorority. Participants showed a sense of pride that they could only have gained from their time in the organization. Even when talking about different NPHC organizations or other chapters participants had a visceral reaction when speaking about the good things that they have accomplished such as public appearances and service initiatives completed by the sorority. As demonstrated below, when one specific chapter or organization in the NPHC is highlighted, it is felt by many members in the entire community.

"Delta Sigma Theta was in the Rose Bowl Parade I don't know if you saw footage from that. It's interesting to go and look at that because of how much it means. I had a friend in Omega and he said to me how moving it was for him it was to see us in the Rose Parade what it meant for all of us even though it was delta doing it, it was making a statement for all of black greek life who we are and what we do and the impact that we have. It was very meaningful for him to observe and he was moved to tears by it. Like oh man we have really come a long way." - [Interviewee \#3 February 2020] 
The interviewee who provided this quote recalled the deep connection that she had with other chapters and other organizations because she did not have a strong biological family support in the area. Though she did not feel adequately supported in her family of origin, she spoke fondly of her Greek family and friendships that she had gained through membership. While recalling the Rose Bowl parade the participant had such a reverence and nostalgic fondness for all of her Greek sisters from those who founded the organizations to those that she is closest to today. She expressed that she just felt grateful to be among their ranks, and that she was proud to be a member of a Black sorority.

Previous members and founders of Black sororities are not only positive influences on current members, but older members locally can have a profound impact on the personal development of a child who will then become a member. Older alumnae members play a large role in preserving the culture and values of the black community as well as their respective greek organizations as can be seen in the following quote:

"[Miss Adams] was like you know one day we're not going to be here and someone is going to have to carry on the legacy of our community and tell their children about our community and so I kind of grew up men of Omega Psi Phi and Phi Beta Sigma and Alpha Phi Alpha and Kappa Alpha Psi in my community".

- [Interviewee \#2, February 2020]

Here the participant highlighted the importance of the church and the community taking care of one another in hard times and in preserving the legacy of their organizations. Not only is the biological family important, but the greek family especially in smaller communities. For these members there is no distinction between biological family or greek family, they are both treated the same. Those who have a familial legacy of Greek organizations are introduced to the organization's values and missions at earlier ages. They will be exposed to scholarship programming, service programming, and are more likely to join and become members of a Black sorority than those who are not biological legacies. The legacy can come from a mother or a sister who is inducted into the organization prior to their kin. For those who do have this biological lineage through sorority are in a sense born to be members of that sorority. Their mothers live their lives by the values and missions of the organizations and affects how they will raise their daughters in accordance to the organization.

"Maybe one day another little girl will look at me and say "I want to be like her" or my own daughter will see the life I've led and the things that I've done in the name of delta and she will want to be like her mom. In spring 2037 I'll be pinning my own daughter because she saw something in me and my sorority sisters that made her want to carry on the legacy”. - [Interviewee \#3 February 2020] 
This intricate connection that legacy members can hold cannot be described through archival data. It is a way of life, and a true essence of their identity as shown by interview data confirming the literature. However, I was able to find one poem in which talked about legacy and the importance of the preservation of the culture and organization stemming from a hymn as seen below:

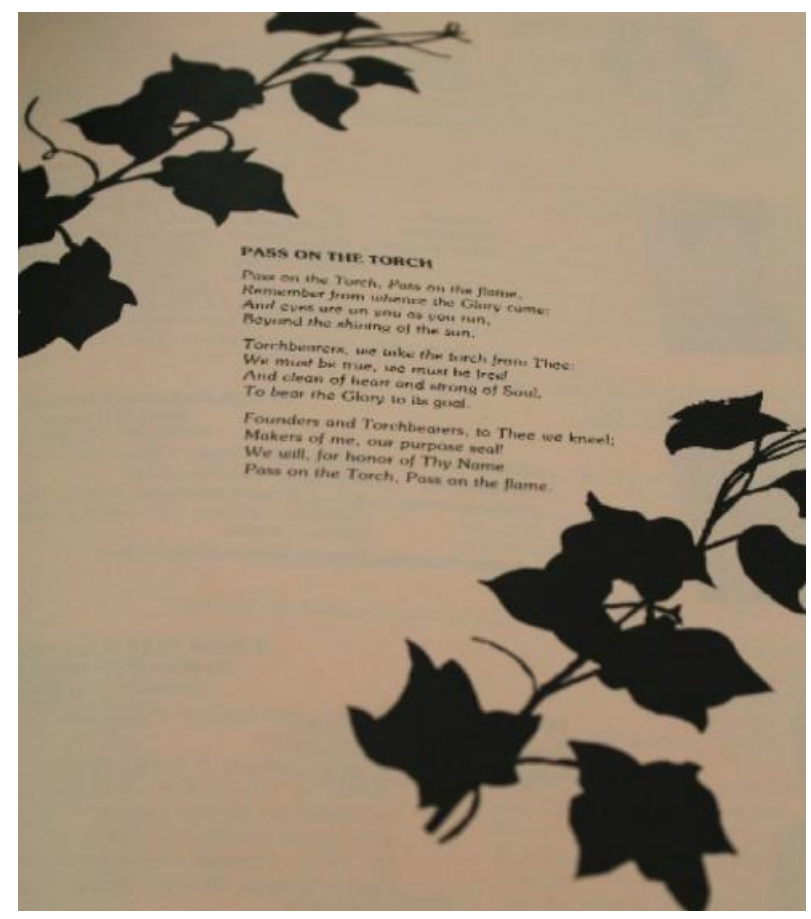

Pass on the Torch, Pass on the flame, Remember from whence the Glory came;

And eyes are on you as you run,

Beyond the shining of the sun. Torchbearers, we take the torch from Thee;

We must be true; we must be free! And clean of heart, and strong of Soul,

To bear the Glory to its goal.

Founders and Torchbearers, to Thee we kneel;

Makers of me, our purpose seal!

We will, for honor of Thy Name

Pass on the Torch Pass on the flame

(Derived from Church Hymn)

Figure 12 Hymn Artifact

This artifact distills not only the importance of preserving the legacy through the passing down of history and values but also the importance of carrying on the legacy of social service and equality which has been fought for since their founders time. Each of these aspects of social service and continuing Black history inherently shape the identity of the organization's members. This object was not used as a boundary object, because it was found in the archive after the onset of the first interview. In an attempt to make all of the interviews mainstream through boundary objects and questions asked, I made the decision to not introduce this artifact into the interview process.

\section{Discussion}

This thesis investigated the perspectives of women in Black sorority alumnae chapters in north central West Virginia. 
Women in Black Sororities join these organizations in efforts of creating lifelong connections through mentorship, scholarship, and service, and to provide a sense of purpose in their lives. To examine this notion of a sense of purpose found in these organizations, the contributing factors highlighted will be discussed. This discussion also covers how Black sorority membership in north central West Virginia differs and coincides with the experiences of members in other geographic locations. This research contributes to the literature in feminist and Black geographies by exploring GLO's and which methods of mentorship women find most valuable to their sense of belonging and identity at predominately white institutions. Much of the literature regarding mentorship focuses on white women, and also does not focus on Black sorority alumnae membership as a possible avenue for mentoring, especially in a predominately white space such as the state of West Virginia.

\subsection{Mentoring Across Organizational Lines}

There is a large body of work that specifically looks at the role of NPHC organizations on Predominately White Campuses (Allen, 2013; Erwin-Toney, 2019; Vance, 2019). However, less of this literature looks at solely women's organizations; and even less at mentorship in Black sororities in the PWI context. PWI's like West Virginia University also have an added layer of analysis; they are land-grant institutions. Land-grant institutions were created under the Morrill Land-Grant act of 1890 which perpetrated a de facto form of segregation (Thorn, 2014). Though the land-grants made junior colleges which in time would turn into HBCU's, the lasting effects of institutions emerging around the end of the Civil War can still be seen at these institutions today. West Virginia University and the state of West Virginia (Gaventa, 1980) has had a reputation of being known as a white state. The university itself was founded on goals of teaching agricultural education. As such, the university was created with one body in mind; the white heterosexual Christian male. Though over time the university has increasingly worked towards achieving diversity at the institution, the vast majority of the campus and surrounding area is still white.

Black geographers such as McKittrick assert that the legacy of the plantation is an underlying theme within the global economy that is highly racialized and continued after emancipation in the US, otherwise known as 'uneven racial geographies. The legacy of the plantation is characteristic of, but not identical to, injustices people of color faced on plantations (McKittrick, 2013). Legacies of oppression are deeply tied to the land. Especially when analyzing, in part, a land grant institution such as West Virginia University, it is important to acknowledge the legacy of the university parallels to the plantation. Both plantation and land grant universities are centered around the possession and cultivation of land. Land grant institutions at their core were created to educate men about agriculture and land possession; excluding women, and people of color because of their inability at the time to own land. This in turn, reproduces the discrimination that the universities were founded on, creating "uninhabitable sites in the 
contemporary" (McKittrick, 2013). This legacy of the plantation in this sense, is still very much prevalent today on the WVU campus. Numbers regarding enrollment and faculty of color remain marginal at best, which in turn helps to keep the university a seemingly uninhabitable place for people of color. This research aimed to look at mentoring as a means for feeling a sense of belonging at a PWI. With numbers of people of color alone stagnating, finding a sense of belonging through the institution itself is not met with ease.

Though the numbers of people of color are small they have contributed to a campus culture of togetherness for students, faculty and staff who have cultural commonalities. However, the greatest agent in creating a home away from home is the NPHC organizations. As indicated by one participant who had experiences at both an HBCU and West Virginia University, the division among organizations at HBCU's may be more prominent, at PWI's such as WVU there is little room to keep the lines intact. Because all of the organizations are founded on similar principles, members from all organizations come together and support the small Black community at the university. As reported by participants, often times sorority women will gather for service events and social gatherings together and not as members of their own individual chapters. This allows access for more women to find mentoring relationships, the entirety of the group must look out for one another when they are so few in number. When speaking about identity in this context, participants viewed themselves more as Black sorority women rather than only a member of their respective chapter. The togetherness among the women regardless of affiliation was one that they expressed a sense of safety in. It is the dissolution of these lines that make mentoring through Black sororities in Morgantown unique. These mentoring relationships unfold in both formal and informal ways.

\subsection{Formal Mentoring in Absence of Institutional Networks}

There is an abundance of literature surrounding formal mentoring structures in universities. The Typical types of mentoring that are outlined in the literature tend to focus on peer-peer, mentorprotégé, and sponsorship (Sands, Parson and Duane, 1991; Dixon-Reeves, 2003; de Janasz and Sullivan, 2004; Sorcinelli and Yun, 2007;). Though the topic has been widely explored through various disciplines, the discipline of geography has focused mostly on the mentoring experiences of white bodies. Most literature published in this area focuses on undergraduate students (Moss, Debres, Cravey, Hyndman, and Masucci, 1999). Literature in geography specifically tends to focus on faculty mentoring (Nakamura et al., 2009) and mentoring as a feminist praxis (Moss, 2019). Results including the word sorority are less than 15 percent of all current literature. Evidence in similar research (Breakfield, 2010; Allison, 2016; Sapp, 2016) has looked at varying aspects of Black sororities, yet not as much on mentoring relationships in predominately white spaces. Though BGLO networks are informal in nature, they are still spaces that provide opportunities for creating more candid mentoring relationships (Kimbrough, 1995; Neumann, 2008). Interviews displayed that formal mentoring is enacted in the realm of education by many 
women in the organization who have similar interests and fields of study. The same then goes for mentoring in the career realm; when a mentor engages in the relationship, she can guide her mentee in applying for jobs or career advancement based on her own experiences.

Mentors that have this cultural connection may have experienced speed bumps along the way that they can warn mentees about, helping them to make better decisions (Patton, 2009). This was confirmed by interviews, when participants spoke explicitly about their experiences and the need for togetherness regardless of chapter affiliation. Mentors in both education and career aid the mentee in creating their own educational or career potential across various landscapes (Vance, 2019). Interviews and archival data revealed the typical jobs a woman of color traditionally had- teachers, social workers, and caregivers. Though each of the participants fit within the realm of 'traditional' career paths for women of color, they noted the increase in the amount of Sorors entering doctoral and professional programs. With more and more Black women being found in doctoral programs, law school, medical school or other avenues requiring higher education, sorority membership will allow them to pave the way for future generations of members. Sorors may be trail blazers in their field and have a wealth of knowledge on the positive and negative aspects of structural politics that can help the mentee, which can then in turn help to form future networks of strong women of color who can mentor other younger women.

As stated previously most literature in geography surrounding mentoring focuses on the white body (Pulido, 2002; Mahtani, 2004). Though research has been done in varying sub disciplines on intersectionality, identity, predominately white institutions, mentoring, and a sense of belonging very few pieces incorporate all these themes into one analysis. In order to be eligible for membership in a Black sorority, you must be enrolled in college or have completed a fouryear degree. Interviews exhibited that it is not uncommon for a Soror to be travelling or moving to a new town to reach out to their larger network. It is expected that Sorors reach out to meet up, show the visitor around, or send something to her hotel room to display sisterhood when moving to a new location. Another formal mentoring act displayed through interviews is providing letters of recommendation for potential members. These letters can be written from any Soror internationally. It is common in these situations for the recommender to attend the initiation ceremony regardless of where in the world it takes place. This display of not only social support but the willingness of the recommender to travel to any location.

In terms of education specifically, mentoring is of the utmost importance in supporting academic achievement in students of color. Membership in a BGLO requires a GPA standard, and as such helps to hold students accountable. Graduate members can serve as these mentors to aid students in gaining their education and representing their respective organizations, while also gaining mentoring from others in the chapter. Especially at PWI's when formal mentoring may be unavailable in the institution, graduate members can serve as peer mentors to undergrads and fellow grad students or administrators. Created spaces of mentorship in these situations can help 
students of color thrive by giving them resources and introduce them to avenues of success in higher education (Erwin-Toney, 2019). With an increase in mentoring relationships within or outside of the academy, over time more and more Black females will feel more at home and have more established spaces to succeed. Information found in the archive corroborated by interviews demonstrates that the structure and values of Black Sororities as organizations remains the same today as it did over 100 years ago. Mentoring and leadership have been at the forefront such organizations for this time as well. Interviewees disclosed that they had been involved in mentoring programs as middle school students put on by various chapters of Black sororities. Generations of Black women have joined these organizations and will be able to join in the future with the same ideals in mind which may help to mitigate the issues of a lack of senior faculty and mentors in these spaces. Though career and educational mentoring is important in the retention of students and student success, other avenues of mentoring such as informal networks may allow for students to feel more accepted in their daily lives. It is through this type of mentoring that this thesis contributes most to the literature.

\subsection{The Importance of Informal Mentoring}

Informal mentoring is often thought of as a relationship that starts as a friendship, or a relationship that forms organically (Lund, Kusakabe, Panda, and Wang, 2016). However, in BGLO's these relationships may form through biological and community ties. BGLO's formed in a time where African American men and women were not able to attend all institutions of higher education, spaces of education and the majority of society was segregated based on race. However, one main mission of all BGLOs is social activism and service. Many social justice movements were experienced- specifically for the context of this project- by women of color such as the women's suffrage movement and the civil rights movement (McKenzie, 2012). Participants reported that a main motivation for continuing involvement in their chapters is that they know by simply being a member they are contributing to Black history. Each instance of resistance and social activism adds to the book of Black history, which creates a strong cultural relationship among people of color. This cultural relationship has led to collective organizing, service, and personal gatherings. Older members of the organization may have experienced the height of these movements, and as such yearn to have the legacy of their struggles to be preserved by younger generations (Neumann, 2008). Older members in this case are often the grandmothers or great grandmothers of current members. Interviews revealed that even if there is not a biological tie to older Sorors, the ties offered by the organization are just as important. In PWI's such as West Virginia University these familial ties to certain organizations are less apparent because of the sheer lack of numbers in each organization. As displayed by the findings of this research, their limited numbers allow all Black sorority women to come together in order to create a space of inclusion and belonging. For women in these organizations there is little difference between biological and sorority family. This shared history and legacy contributes to the informal relationships that are enacted within membership in a BGLO. 
Often times, women may have biological ties to the organizations through their parents, aunts, or other caregivers allowing them to be exposed to the NPHC at a younger age. Mentoring then can start at young ages through extended family members or community members who instill the values and expectations into the children around them. When women come to college, often these relationships are carried out over longer distances making a predominately white campus a place far away from their home place and belonging.

\subsection{Mentoring for a Sense of Belonging}

The concept of a sense of belonging in geography emerged towards the end of the civil rights movement and was more heavily studied in times of social unrest. Though the most cited scholar on the topic in geography (Tuan, 1997) was considered a minority, the discipline itself was still inherently white. As such, the concepts of a sense of belonging and humanistic geography tended to favor those of the dominant group in society- those who were white and more often than not male. While feminist geographers were concerned with the study of the home as a physical space, Tuan conceptualized it as a symbolic space; bell hooks attributes this conceptualized space to be one of familiarity, comfort, security, and emotional attachment" (hooks, 2010: 646). This research presents that Black sororities themselves may have a physical space that they meet for monthly meetings and service projects, however, the space of the sorority itself is an example of a symbolic space. This symbolic space provides women with formal and informal modes of mentorships, friendships, security, and emotional attachment through Black history and family legacy. Were women not to have the experience of being in a Black sorority it would be plausible to deduct that they would not have nearly as an enriching experience in life without their sorority sisters. When one feels 'at home' whether that be at their physical place of residence or not, is what contributes to a person's sense of belonging.

Findings confirmed that to be in a Black sorority is to participate in a facet of black history, and Black history in the making. Black sororities were modeled after African cultural traditions and resistance to intersectional oppression (Phillips, 2005). Interviewees reported that the moment that one is initiated into the sorority she remains a member for life no matter the amount of her active involvement. This data aligns with the notion that these spaces provide a home place away from biological families and in some instances can create stronger bonds than the biological family because of the added aspects of service and sisterhood (Neumann, 2008). The legacy that is carried on through each act of service goes back to early political organizing during the civil rights movement. Lines of legacy involvement in NPHC organizations can sometimes span generations of Black men and women. These lines continue through current members children where they are raised with the principles of leadership, service, and sisterhood from a very young age. Each woman who enters into a Black sorority then helps to keep creating Black history. 
Work particularly in Black geographies highlights how the conceptualization of Black history is shaped by hegemonic structures and is carried on through such a legacy. For example, Shabazz's work on the prison industrial complex highlights the idea of 'spatialized blackness' which is a mechanism of control carried out through and by those who wished to keep people of color marginalized; these actions include policing, containment, and establishment of lesser spaces (Shabazz, 2015). Shabazz also utilizes similar methods to analyze archive data to document "how social forces like racism, patriarchy, neoliberalism, colonialism, and punishment, for example, are mapped onto landscapes and people" (2015, p. 4). Historical geographers have focused on the racialization and gendering of various landscapes and how bodies of color respond and react to these various forms of spatial organization. The inception of Black sororities is a concrete example of this phenomena, carving out spaces in response to forms of spatial organization through the need to separate education for African Americans through Historically Black Colleges and Universities (Neumann, 2008). Because public spaces have long reproduced disciplinary procedures from the prison industrial complex (Shabazz, 2015), it is of the utmost importance to create spaces for women of color to thrive utilizing their own ways of place making rather than white forms of place making that have systematically kept women of color out of the conversation. The legacy of disciplinary action stems from the 'ability to contain and incapacitate Black people" through plantations (Shabazz, 2016: 6). The legacy of the plantation has been studied heavily by other scholars in Black geographies such as Katherine McKittrick. As stated earlier, a Black sense of place and existence has historically been reduced to an identical experience directly correlating with the legacy of social stratification from plantations. The social schemas of the plantation are the blueprints for social stratification and processes that influence Black sense of place today (McKittrick, 2011). More specifically, Black women's sense of belonging is not static; the contexts that aid in the construction of Black femininity show how the world itself has profited from consolidating and 'othering' their experiences (McKittrick, 2006). It is this sense of 'othering' and the blueprints continued from the plantation that construct the way that Black women continue to operate and create a sense of place.

\subsection{Identity}

Studies of identity have been prevalent in disciplines such as psychology, sociology and geography for quite some time. Today, studies on identity are more focused on ingroup and outgroup relations; for the context of this research the ingroup tends to be white bodies, and the outgroup tends to be bodies of color. When asking someone the question "who are you?" many will respond with a description of their occupation first (Unruh, 2004). For Black sorority members organization and identity are not separate entities. Membership in an organization is often times one of the first lines of explanation of a member's identity. Through sisterhood, family ties, service, and black history, each member plays their own part in the larger 
organizational structure helping to not only inform their own identity but the identity of the organization itself. However, the formation of one's identity is much more than a career. Factors that also contribute to one's identity include gender, class, religion, ethnicity, and sexuality. These factors are not solely expressed on their own but are expressed as a perfectly engineered web of factors; a person is not 'whole' without the sum of their parts.

The ingroup in the context of PWI's is the white male hegemonic structure. For the entirety of their history, these institutions were and are most often led by white heterosexual Christian men. This does not deviate from the universities original intended purpose. As time has gone on, more and more women of color are seen on college campuses, however this does not negate the history that universities hold in discrimination. As Yuval-Davis states, "belonging is not a story, but is looking at a story in a sense of how a person feels; those who feel threatened cannot feel a sense of belonging" (2006: 202). Regardless if one feels as though they belong or not, this process in itself contributes to the formation of one's identity. Mentoring in Black sororities is directly impact's identity formation. Members have an unyielding sense of pride gained from being a part of the larger organization, and of the NPHC. For many women in the research looking back on the organizations history and seeing how far they have come elicited visceral reactions. The impact that membership has on a woman is unparalleled to other experiences throughout the lifetime. As many members are exposed to NPHC organizations at a young age, the people who they looked up to as children were the pillars of their communities. They were the post man, the first lady of their churches, their teachers; each one of them had an instrumental partaking in serving as role models and later informing their identities. The importance of preserving the culture, organization, and history is engrained in them from a young age. The preservation becomes a way of life and is inseparable of identity.

All members of society have a racialized identity which stems from this sense of belonging or not (Tatum, 1997). Each of the dimensions of a person's identity (race, gender, social status, sexuality, etc.) intersect and interact. It would be impossible to look at identity formation without recognizing the standpoint of the person in relation to the outside world (Collins, 2009). Those who have been deemed 'other' find a sense of belonging in Black sororities and are able to continue to develop aspects of their identity in a safe environment.

\section{Conclusion}

This research has analyzed Black sorority membership as a means for mentorship in Predominately White Institutions (PWI's) in the absence of formal mentoring networks through education, and career development. Black sororities offer various types of mentorship including formal and formal avenues. Because of the context at West Virginia University, Black sorority women are less concerned with their individual affiliations and more so with their collective 
membership as a member of the NPHC. Because of a lack of numbers in the NPHC at the university, women feel a sense of belonging collectively to the NPHC. In terms of mentoring, the physical divisions of each organization dissolve in order for mentoring to be enacted across organizations. Participants spoke to their involvement in Black sororities as a contribution to the legacy and history of Black history overall. The avenues in which these contributions are made are through informal means of mentoring across organizations.

The findings have highlighted that in predominately white spaces, Black sorority alumnae membership is essential for mentoring relationships to form when they are not available or adequate through formal means. Black sorority membership has also been presented to significantly contribute to a woman of color's sense of belonging in predominately white spaces. Lastly, it has been exhibited that being in a Black sorority allows women to be a part of Black history and as such helps to shape their identity as woman of color. These aspects of identity are passed down to their children and through involvement in their local communities.

This research in particular aligns with Alexander and Bodenhor's 2012 piece which does not discredit that Black women can thrive with white mentors but exhibits that peer-peer mentoring on a deeper cultural and organizational level is more advantageous to mentoring relationships. The research also expands on the arguments made by Vance (2019), Johnson (2018), and Ford (2017). Vance expands on literature regarding a sense of belonging, but not identity formation; Johnson expands on literature on the self-perceived togetherness at a PWI, and Ford expands on literature of the legacy of land-grant institutions. It is at the intersection of these three works that this project has contributed to the literature on Black Greek Letter Organizations. It has also attempted to fill a gap in geographic literature that has produced little work on Black sororities as an avenue for mentoring relationships at Predominately White Institutions.

Limitations faced while conducting research were a less than anticipated pool of potential interviewee's, and the COVID pandemic. Many women who attend WVU do not remain in the area because larger metropolitan areas provide more job opportunities. Those who have stayed tended to be starting families and careers and were hard pressed for time to be interviewed. Lastly, the COVID pandemic of 2020 impacted the tail end of the research in regard to potential interviews being cancelled, and member checking needing to be completed via Zoom.

Future studies regarding the topic are needed to better understand how various forms of mentoring through Black sororities help to bridge the gap between university goals of diversity, and the notion of inclusion. Participants disclosed the need for more research to be completed in order for universities as a whole to understand their organizations. Because NPHC organizations are located at both the undergraduate and graduate level, mentoring in these organizations could contribute to the larger mentoring networks for all students of color at PWI's. 


\section{Appendices}

\subsection{Appendix B- Glossary of Terms}

AAG-American Association of Geographers, the professional organization for the discipline of geography.

Affirmative Action- The practice or policy of favoring individuals belonging to historically marginalized groups (Loury and Garman, 1993).

Coding- Process of transforming raw data into a standardized format for data analysis by identifying recurrent words, concepts or themes (Clifford, Cope, Gillespie and French, 2016).

Covert Racism- form of racial discrimination that is seen as less obvious through subtleties and concealed in the structure of society (Bonilla-Silva, 1997).

Credibility- use of persistent observations, triangulation (of data, methods, theories and investigation) and member checks (Mason, 2017).

Criterion Sampling- sample fits a certain criterion for participation in the study (Gray, 2018)

Data Saturation- point at which data collection can cease, because data has become repetitive with the emergence of no new themes or ideas (Gray, 2018).

Discourse Analysis- study of how both spoken word and written language is used in social contexts (Mason, 2017).

Gatekeepers- individuals who have the power or influence to grant or refuse access to a field or research setting (Gray, 2018). 
Member Checking- Process where the researcher checks with participants informally for accuracy during data collection (Clifford, Cope, Gillespie and French, 2016).

Overt Racism- Public expressions of racism through word or actions (Bonilla-Silva, 1997).

Participant Review- Process by which the researcher asks each participant to review the researcher's synthesis of all interviews with the person for accuracy of representation (Mason, 2017).

Passkey Program- outreach program designed to help Black freshman adapt to university life (West Virginia University)

Racialized Fatigue- describes the psychological and social stress that people of color experience existing on a predominately white campus. (Smith, Huang, and Franklin, 2011).

Reflexivity- The researcher's own reflections on their actions and observations in the field and their feelings become part of the data themselves (Mason, 2017)

Risk Assessment- Assessment done by evaluating the possible psychological risk to participants about talking about their experiences (Clifford, Cope, Gillespie and French, 2016).

Semi-Structured Interview- verbal exchange where one person, the interviewer, attempts to elicit information from another person by asking questions (Clifford, Cope, Gillespie, and French, 2016).

Snowball Sampling- sampling method where the researcher identifies a small number of subjects, who, in turn identify others in the population. Used in situations where the focus of a study is a sensitive issue and therefore requires the knowledge of insiders to locate respondents for the study (Gray, 2018).

Theoretical Sampling- Set of procedures where the researcher manipulates their data generation, analysis, theory and sampling activities interactively during the research process to gain a greater extent than statistical sampling (Mason, 2017). 


\subsection{Appendix B- Interview Guide}

1. Personal

a. Where are you from? What brought you to the greater Morgantown area?

b. What and where did you study?

c. What led you to choose this profession/major?

d. Did you feel adequately supported by an advisor in your major?

e. When did you hear about historically black sororities?

2. Using Boundary Objects (See Below-These questions will summarize the boundary object section)

a. Are there any emotions/memories that come up for you regarding these artifacts?

b. What kinds of materials do you believe should be represented of your organization in the archives?

c. Is there anything you would like to contribute to the archive?

3. Sorority Membership

a. What types of interactions did/does your sorority experience provide you with?

(i.e. support system, friendships, network of people)

b. What types of places do you gather with your sisters? Has this changed over time?

c. Who is the most influential person in your sorority life?

d. With whom do you spend your time? 
e. Where do you spend it with them and when? Is this free time or study/professional time?

f. How does your sorority membership influence various aspects of your life (i.e. home, work, etc.)?

g. How far do you travel for sorority events/how often do you participate in events?

4. $\quad$ Living in North Central West Virginia

a. What is your sense of racial diversity in West Virginia?

b. How has that changed over time, if at all?

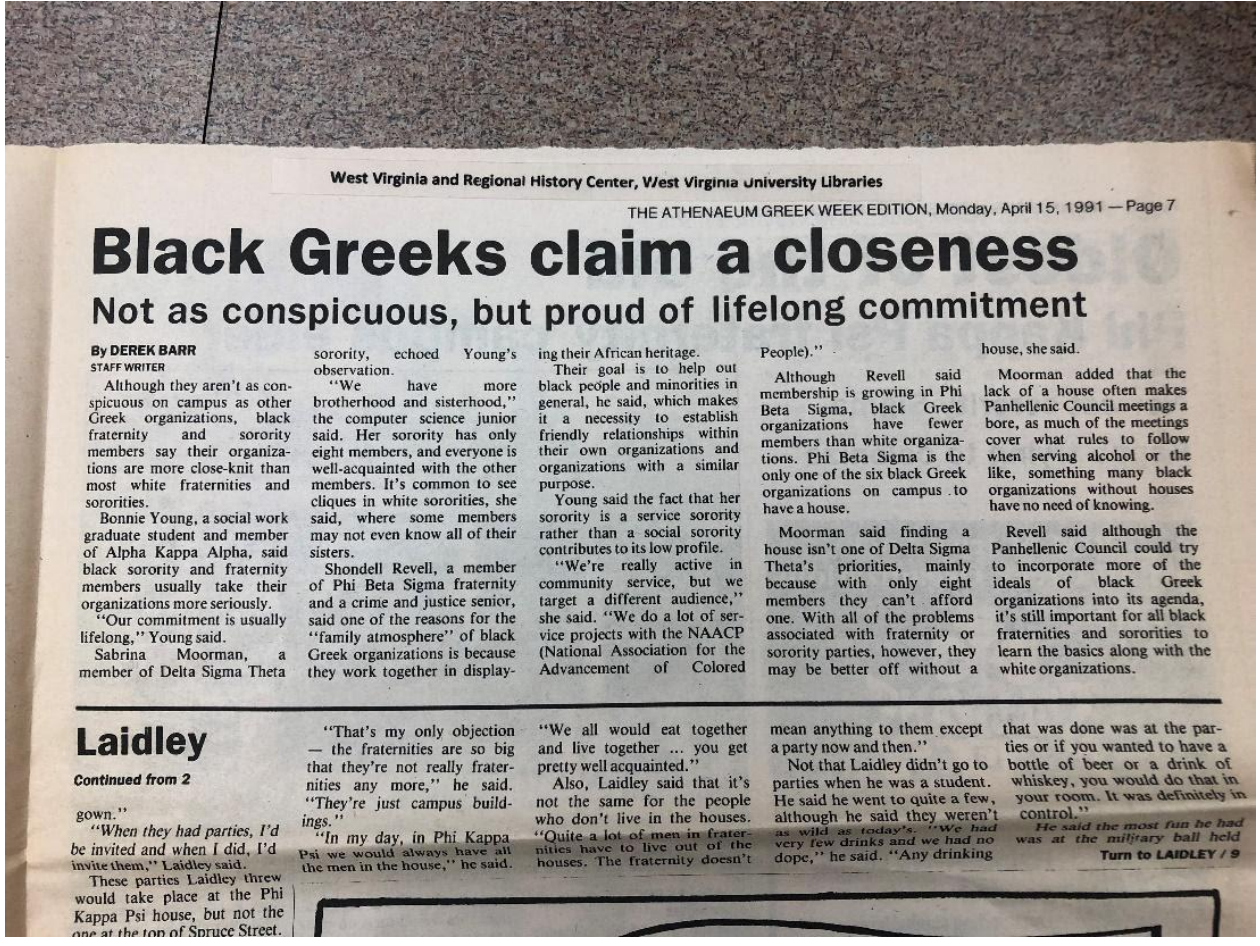

Newspaper article from the student newspaper "The Daily Athenaeum" Greek Week Edition, April 15,1991. Article depicts the cultural climate at WVU at the time and the differences between traditional and Black sororities

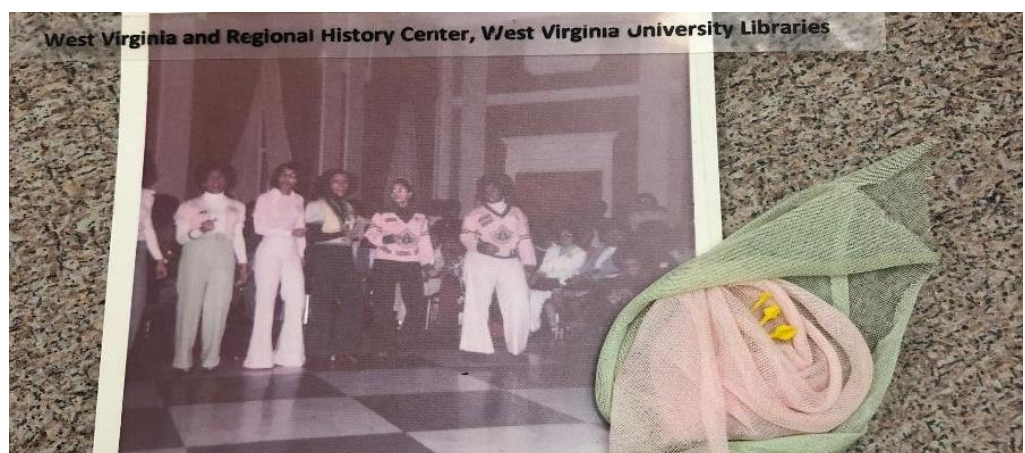

Picture of Alpha Kappa Alpha women at a social gathering in the 1970's, and a routineer from the event 


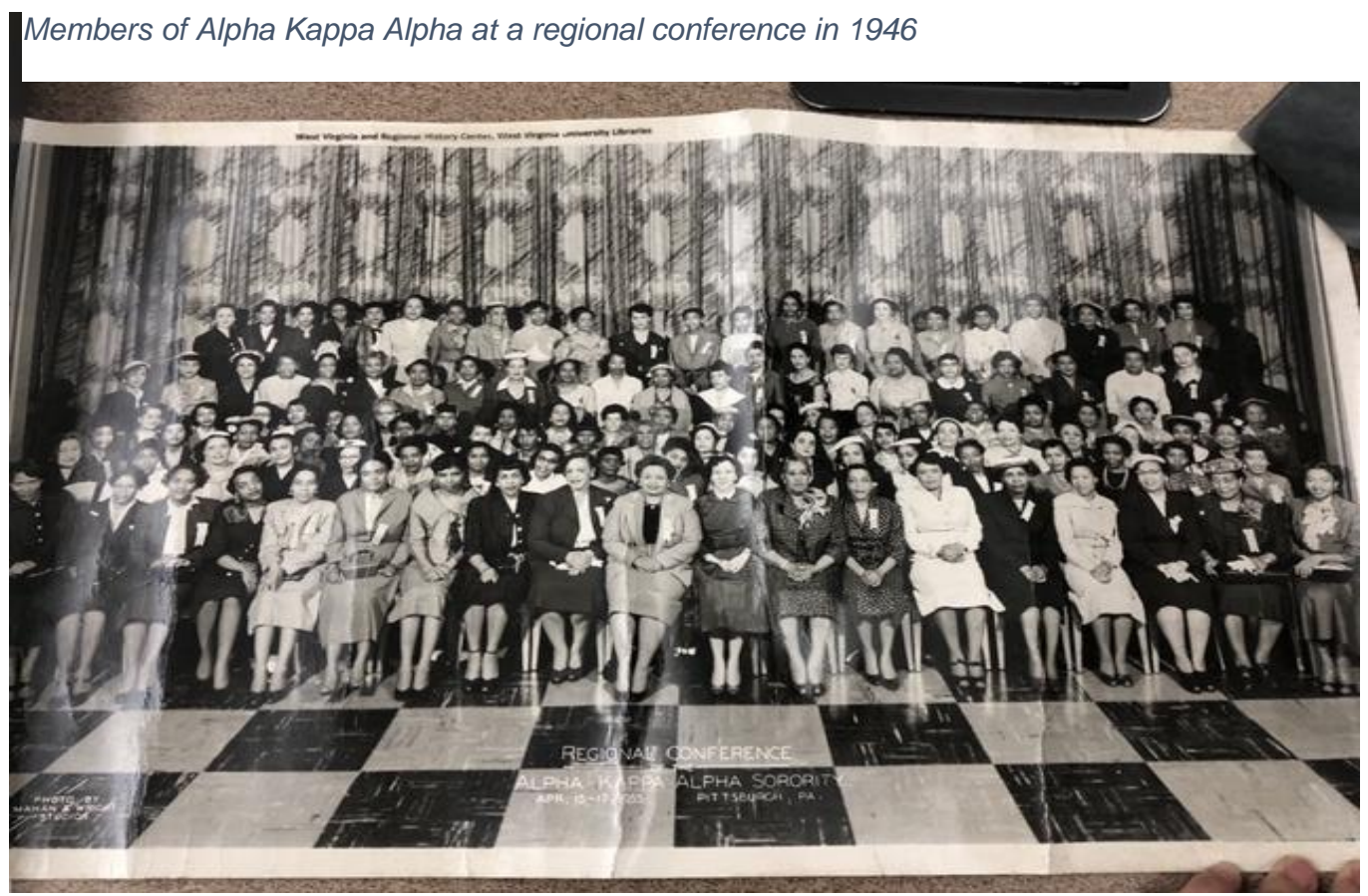

Alpha Kappa Alpha Sorority meeting agenda from January 1959 which entails the agenda for the meeting as well as future and current projects
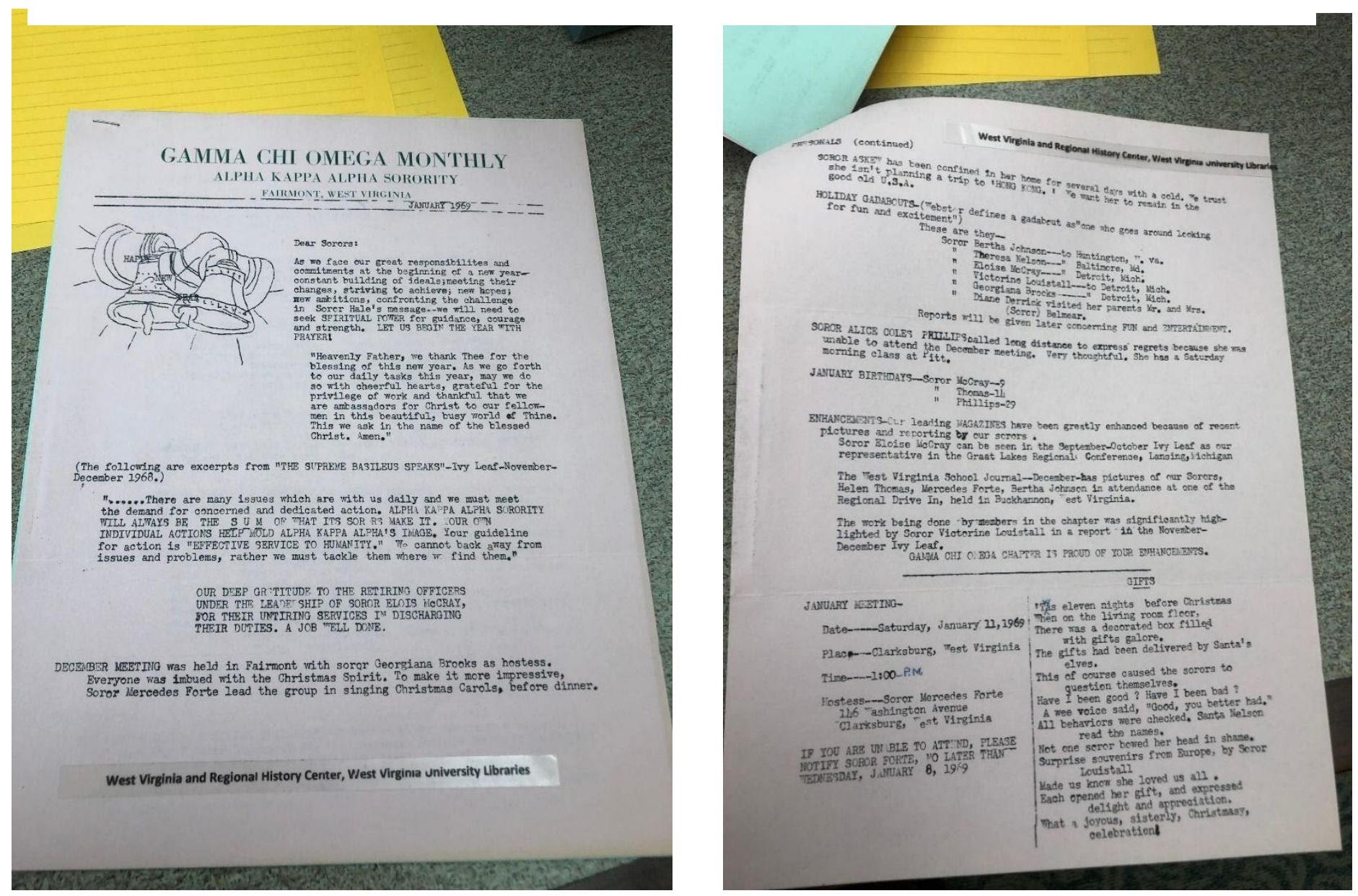
Figure 2 Alpha Kappa Alpha Members travel to California from Pittsburgh to Boule their international conference

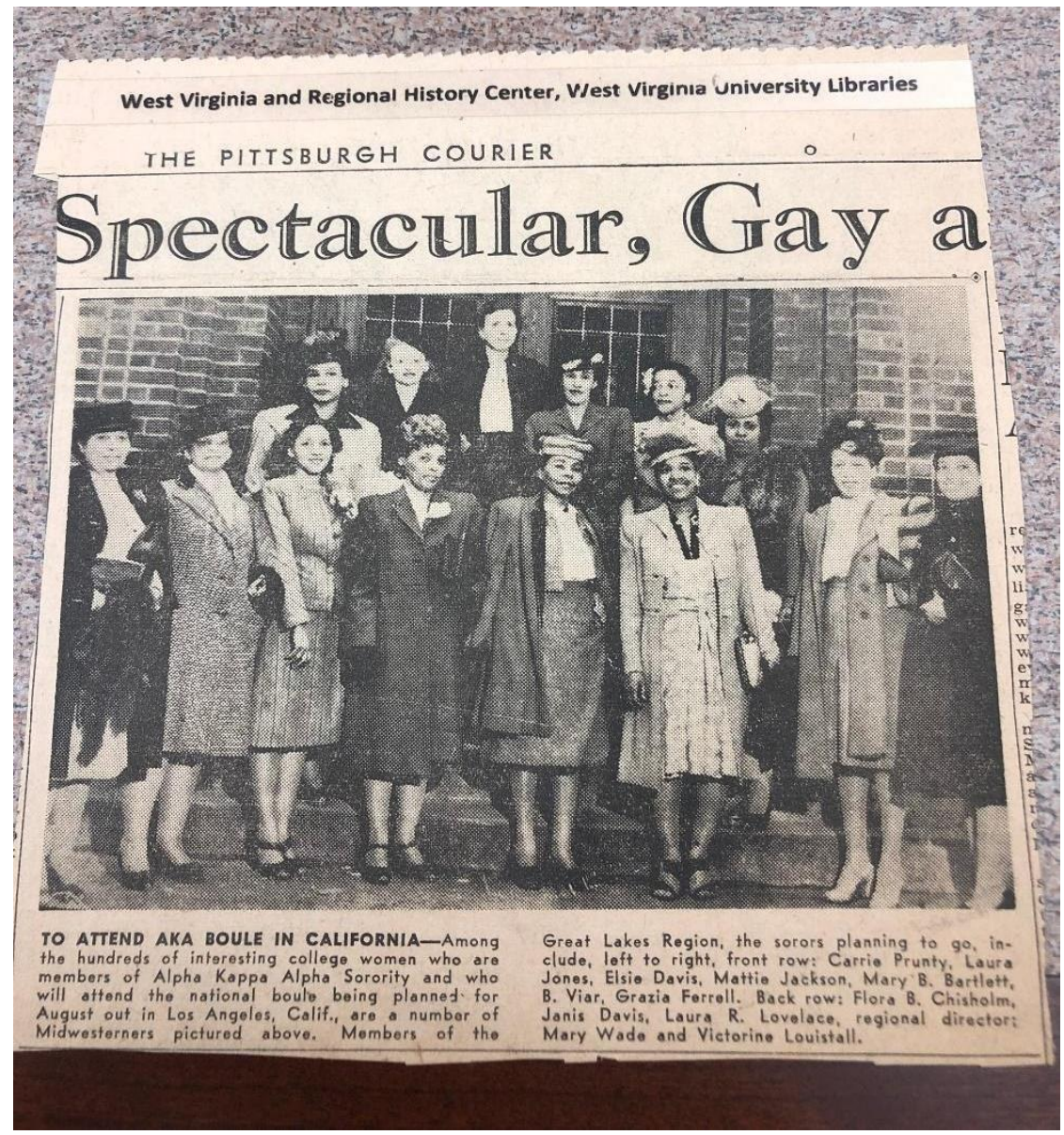




\title{
9.3 Appendix C- IRB Materials
}

\author{
West Virginia University \\ Office of Research Integrity and Compliance \\ 838 Chestnut Ridge Road \\ Acknowledgement of Exemption
}

$09 / 24 / 2019$

To: Martina Caretta

From: WVU Office of Research Integrity \& Compliance

Protocol Type: Exempt Approval Date: 09/24/2019

Submission Type: Initial Expiration Date: 09/24/2024

Funding: N/A

WVU Protocol \#: 1907641479

Protocol Title: Black Sororities at West Virginia University: A Case Study of Placelessness through Housing and Mentorship

The West Virginia University Institutional Review Board has reviewed your submission of Exempt protocol 1907641479. Additional details regarding the review are below:

This research study was granted an exemption because the Research involves educational tests, survey procedures, interview procedures or observation of public behavior and (i) information obtained is recorded in such a manner that human subjects cannot be identified, directly or through identifiers linked to the subjects; and (ii) any disclosure of the human subjects responses outside the research could not reasonably place the subjects at risk of criminal or Civil liability or be damaging to the subjects financial standing, employability, or reputation [45 CFR 46.101(2)]. All exemptions are only good for three years. If this research extends more than three years beyond the approved date, then the researcher will have to request another exemption. The following documents have been acknowledged for use in this study and are available in the WVU+kC system: The following documents were reviewed and approved for use as part of this submission. Only the documents listed below may be used in the research. Please access and print the files in the Notes \& Attachments section of your approved protocol.

- Cover Letter_IRB092219.docx

Protocol \#: 1907641479 Phone: 304-293-7073

FWA: 00005078 Fax: 304-293-3098

IORG: 0000194 Email: 1RB@ mail.wvu.edu

- Interview Questions.docx 
- Counseling Services Referral_IRB.docx

WVU IRB acknowledgement of protocol 1907641479 Will expire on 09/24/2024.

If the study is to continue beyond the expiration date, a renewal application must be submitted no later than two (2) weeks prior to expiration date. It is your responsibility to submit your protocol for renewal.

Once you begin your human subjects research, the following regulations apply:

1. Unanticipated or serious adverse events and/or side effects encountered in this research study must be reported to the IRB within five (5) days. using the Notify IRB action in the electronic protocol.

2. Any modifications to the study protocol should be submitted only if there will be an increase in risk to subjects accompanying the proposed Change(s).

3. You may not use a modified information sheet until it has been reviewed and acknowledged by the WVU IRB $1 \mathrm{~m}$ to implementation.

The Office of Research Integrity and Compliance will be glad to provide assistance to you throughout the research process. Please feel free to contact us by phone, at 304.293 .7073 or by email at IRB @ mail.wvu.edu.

Sincerely,

Lile Ast

IRB Administrator 


\section{References}

Adams-Hutchenson, G. and Johnson, L. 2019. Flourishing in fragile academic workspaces and learning environments: Feminist geographies of care and mentoring. Gender, Place and Culture, 26(4): 451-467

Allen, D. Lawhon, M., \& Pierce, J. 2018. Placing race: On the resonance of place with Black geographies. Progress in Human Geography 43(6): 1001-1019.

Alcoff, L. 1996. Feminist theory and social science: New knowledges, new epistemologies, In Body/Spaces: Destabilizing geographies of gender and sexuality. N. Duncan (ed). Routledge. 13-27.

Alexander, Q. R., \& Bodenhorn, N. (2015). My rock: Black women attending graduate school at a southern predominantly white university. Journal of College Counseling, 18, 259-274. doi:10.1002/jocc.12019

Allison, D.J. 2016. We matter, we're relevant and we are Black women in sororities: An exploration of the experiences of Black sorority members at a predominately white institution. (Dissertation) retrieved from: https://digitalcommons.unl.edu/cgi/viewcontent.cgi?article $=1274 \&$ context=cehsedaddiss

Antonsich, M. 2010. Searching for belonging- An analytical framework. Geography Compass, 4(6): 644-659

Association of American Geographers (AAG). 2017. Profiles of AAG membership, 2017. Online publication. Accessed: April 20, 2019.

Arefin, M. R., Hennessy, E., McClintock, N., Mollett, S., \& Van Sant, L. 2018. Historical geographies of, and for, the present. Progress in Human Geography: 1-21 doi:10.1177/0309132518799595

Asher, N. 2007. Made in the (multicultural) U.S.A.: Unpacking tensions of race, culture, gender, and sexuality in education. Educational Researcher, 36(2), 65-73. doi:10.3102/0013189x07299188

Baldwin, C.P. \& Griffin, M.D. 2014. Challenges of race and gender for black women in the academy. In: Disrupting the culture of silence: Confronting gender inequality and making change in higher education. De, W.K. \& Stepnik, A. (eds).

Blackwell, J.E. 1983. Networking and mentoring: A study of cross-generational experiences of Black graduate and professional schools. Atlanta, GA: Southern Education Foundation.

Bondi, L. Gender and geography: Crossing boundaries. Progress in Human Geography, 17(2): 241-246.

Bondi, L. and Davidson, J. 2004. Situating gender. In Nelson, L. and Seager, J. (eds) A companion to feminist geography, Malden, MA: Blackwell, 15-31

Bonilla-Silva, E. 1997. Rethinking Racism: Toward a Structural Interpretation. American Sociological Review, 62(3), 465. doi:10.2307/2657316 
Bova, B. 2000. Mentoring revisited: The Black woman's experience. Mentoring and Tutoring, $8(1): 5-16$

Breakfield, F.A. 2010. Encircled by sisterhood: Mentoring experiences of African American women in Delta Sigma Theta Sorority (Doctoral Dissertation). Retrieved from: https://digitalcommons.georgiasouthern.edu/etd/

Brown, 2018. Black geographies: Mapping Black spaces and places.

Brown, R. H., \& Davis-Brown, B. 1998. The making of memory: the politics of archives, libraries and museums in the construction of national consciousness. History of the Human Sciences, 11(4), 17-32. doi:10.1177/095269519801100402

Bastia, T. 2014. Intersectionality, migration and development. Progress in Development Studies, 14(3), 237-248. doi:10.1177/1464993414521330

Butler, J. 1990. Gender Trouble. Routledge. London.

Caretta, M. A. 2014. Situated knowledge in cross-cultural, cross-language research: a collaborative reflexive analysis of researcher, assistant and participant subjectivities. Qualitative Research, 15(4), 489-505. doi:10.1177/1468794114543404

Cho, J. and Trent, A. 2006. Validity in qualitative research. Qualitative Research. SAGE. London.

Clifford, N., Cope, M., Gillespie, T. and French, S. 2016. Key Methods in Geography, $3^{\text {rd }}$ Edition. Sage: London.

Collins, P.H. [1996] 2006. What's in a name? Womanism, Black feminism, and beyond. In L. Phillips (Ed.) The Womanist Reader, pp: 57-68. New York, NY: The New Press.

Collins, P.H. 1997. Comment on Hekman's 'Truth and method: feminist standpoint theory revisited": Where's the power? Signs, 22(2): 375-381

Collins, P.H. 1989. The social construction of Black feminist thought. Signs, 14(4): 745-773.

Cope, M. 2005. A history of qualitative research in geography. In The SAGE Handbook of Qualitative Geography. DeLyser, D., Herbert, S., Aitken, S., Crang, M., and McDowell (eds). SAGE: London.

Crenshaw, K. 1989. Demarginalizing the intersection of race and sex: A Black feminist critique of antidiscrimination doctrine, feminist theory and antiracist politics. University of Chicago Legal Forum 1989(1), 139-167.

Daily Athenaeum, 1991, April 15. Black Greeks claim a closeness not as conspicuous, but proud of lifelong commitment.

Datta, A. and Lund, R. 2018. Mothering, mentoring, and journeys towards inspiring spaces. Emotion, Space and Society, 26: 64-71

Darwin, A. and Palmer, E. 2009. Mentoring circles in higher education. Higher Education Research and Development, 28(2): 125-136

Delaney, D. 2002. The space that race makes. The Professional Geographer, 54(1): 6-14.

Delta Sigma Theta Inc. 2015. Constitution and Bylaws. 52nd National Convention Amendments. Washington, D.C.

De Janasz, S.C. and Sullivan, S.E. 2004. Multiple mentoring in academe: Developing the 
professorial network. Journal of Vocational Behavior. 64: 263-283

De Los Reyes, G., \& Rich, P. 2003. Housing Students: Fraternities and residential colleges. The ANNALS of the American Academy of Political and Social Science, 585(1), 118123. doi: $10.1177 / 0002716202238570$

Dixon-Reeves, R. 2003. Mentoring as a precursor to incorporation: An assessment of the mentoring experiences of recently minted PhD's. Journal of Black Studies. 34(1): 12-27

Dominion Post, 1982 Summer. Racism on Campus. Series Summer 1982

Domingue, A.D. 2014. "Our leaders are just we ourself": Black women college student leaders' experiences with oppression and sources of nourishment on a predominately White college campus. Equity \& Excellence in Education, 48(3): 454-472

Domosh, M. 1998. Geography and gender: home, again? Progress in Human Geography, 22(2):276-282

Dyck, I. 2005. Feminist geography, the 'everyday', and local-global relations: hidden spaces of place-making. The Canadian Geographer, 49(3): 233-243.

Eaves, L. 2017. Black geographic possibilities: On a queer Black south. Southeastern Geographer, 57(1): 80-95

Eby, L.T. and Lockwood, A. 2005. Prote'ge's and mentors' reactions to participating in formal mentoring programs: A qualitative investigation. Journal of Vocational Behavior, 67, $441-458$

England, K.V. 2003. Towards a feminist political geography? Political Geography, 22: 611-616.

England, K.V. 1994. Getting personal: Reflexivity, positionality and feminist research. The Professional Geographer, 46(1).

Erwin-Toney, T. 2019. The hidden value of national Panhellenic organizations at predominately white institutions: Racial identity and impacts (Dissertation). Retrieved from:

Faria, C., Falola, B. Torres, R. and Henderson, J. 2019. A long way to go: Collective paths to racial justice in Geography. Professional Geographer. Accepted.

Falconer Al-Hindi, K., and H. Kawabata. 2002. Toward a more fully reflexive feminist geography. In Feminist geography in practice: Research and methods, ed. P. Moss, 10315. Malden, MA: Blackwell.

Fem-Mentee Collective: Bain, A.L. et al. 2017. Emotional masking and spill-outs in the neoliberalized university: A feminist geographic perspective on mentorship. Journal of Geography in Higher Education, 41(4): 590-607.

Franks, M. 2002. Feminisms and cross-ideological feminist social research: Standpoint, situatedness and positionality- developing cross-ideological feminist research. Journal of International Women's Studies, 3(2).

Fleming, J. 1984. Blacks in College: A Comparative study of students' successes in Black and white institutions. San Francisco: Jossey-Bass.

Gaither, S.E. 2017. The multiplicity of belonging: Pushing identity research beyond binary thinking. Self and Identity, 17(4): 443-454 
Gasman, M. and Abiola, U. 2016. Colorism within the Historically Black Colleges and Universities (HBCUs). Theory Into Practice, 55: 39-45.

Gaventa, J. 1980. Power and powerlessness: quiescence and rebellion in an Appalachian valley. University of Illinois Press

Gillespie, A. and Cornish, F. 2010. Intersubjectivity: Towards a dialogical analysis. Journal for the Theory of Social Behavior, 40(1)

Gilmore, R. W. 2002. Fatal couplings of power and difference: Notes on racism and geography. The Professional Geographer, 54(1): 15-24

Gillen, J. Ziegler, A.D., Friess, D.A., and Wasson, R. 2014. Geography's role in nurturing postgraduate students. The Geographic Journal.

Gillon, K.E., Beatty, C.C. \& Salinas, C. (2019). Race and racism in fraternity and sorority life: A historical overview. New Directions for Student Services. 165(1): 9-16.

Ginn, F. 2014. "Being like a researcher": Supervising Master's dissertations in a neoliberalizing university. Journal of Geography in Higher Education, 38(1): 106-118.

Grant, C. A., \& Zwier, E. 2011. Intersectionality and student outcomes: Sharpening the struggle against racism, sexism, classism, ableism, heterosexism, nationalism, and linguistic, religious, and geographical discrimination in teaching and learning. Multicultural Perspectives, 13(4), 181-188.

Grasgreen, A. 2013. It's not just Alabama. Retrieved from https://www.insidehighered.com/news/2013/09/19/segregated-sororities-not-limitedalabama-experts-say

Gray, D. E. 2018. Doing Research in the Real World, 4th edition. Sage: London.

Green, E. 1998. 'Women doing friendship': An analysis of women's leisure as a site of identity construction, empowerment and resistance. Leisure Studies, 17(3): 171-185

Gregory, D., Pratt, G., and Watts, M. 2000. The Dictionary of Human Geography, Oxford: Blackwell.

Guiffrida, D.A. and Douthit, K.Z. 2010. The Black student experience at predominately white colleges: Implications for school and college counselors. Journal of Counseling and Development, 88: 311-318.

Haraway, D. J. 1988. Situated knowledges: The science question in feminism and the privilege of partial perspective. Feminist Studies, 14(3), 575-599. https://doi.org/10.2307/3178066

Harper, S.R., and Hurtado, S. 2007. Nine themes in campus racial climates and implications for institutional transformation. In S.R. Harper and L.D. Patton (eds.), New Directions for Student Services, No: 120. Responding to the realities of race on campus. Jossey-Bass, San Francisco, CA.

Harris, F. 1999. Centricity and the mentoring experience in academia: An Afrocentric mentoring paradigm. The Western Journal of Black Studies, 23(4): 229-235

Harris, J. C., Barone, R.P. \& Finch, H. 2019. The property functions of whiteness within 
fraternity and sorority culture and its impact on campus. New Directions for Student Services, 165: 17-27.

Hartstock, N. 1997. The feminist standpoint: developing the ground for a specifically feminist historical materialism. In: L. Nicholson (ed) The second wave: A reader in feminist theory. London. Routledge

Hawkins, R., Manzi, M., and Ojeda, D. 2013. Lives in the making: Power, academia, and the everyday. ACME.

Hawthorne, C. \& Heitz, K. 2018. A seat at the table? Reflections on Black geographies and the limits of dialogue. Dialogues in Human Geography, 8(2): 148-151.

Henry, M. 2017. Ivory towers and ebony women: The experiences of Black women in higher education. In Changing the Subject: Women in Higher Education, S. Davies, C. Lubelska, and J. Quinn (eds). Taylor and Francis.

Hernandez, M.D. 2008. Sisterhood beyond the ivory tower: An exploration of Black Sorority alumnae membership. In: Gregory S. Parks (ed.) Black Greek Letter Organizations in the Twenty First Century: Our Fight has just begun. University of Kentucky Press,

Holloway, S.L. and Valentine, G. 2000. Children's Geographies: Playing, Living, Learning. (eds) London: Routledge.

Hopkins, P., and Noble, G. 2009. Masculinities in place: situated identities, relations and intersectionality. Social \& Cultural Geography, 10(8), 811819. doi:10.1080/14649360903305817

hooks, B. 1995. Killing Rage: Ending Racism, Henry Holt and Company, New York.

hooks, B. 1992. Representing whiteness in the Black imagination. In: The Cultural Geography Reader. T.S. Oakes and P.L. Price (eds). Routledge. New York. 374-379.

Johnson, 2018. We are one: a phenomenological study of the self-perceived experiences of Black students in the National pan Hellenic council at a predominately white institution and historically black university in the southeast. (Dissertation) Retrieved from https://digitalcommons.lsu.edu/cgi/viewcontent.cgi?article=5791\&context=gradschool_th $\underline{\text { eses }}$

Johnston-Anumonwo-I. 2019. Mentoring across difference: success and struggle in an academic geography career. Gender Place and Culture, 26(12)

Kaplan, D.H. 2018. Navigating ethnicity: Segregation, placemaking and difference. Rowman \& Littlefield: New York

Kimbrough, W. 1995. Self-Assessment, participation, and value of leadership skills, activities, and experiences for Black students relative to their membership in historically Black fraternities and sororities. The Journal of Negro Education, 64(1), 6374. doi: $10.2307 / 2967285$

Kobayashi, A. and Peake, L. 2007. Unnatural discourse. 'Race' and gender in geography. Gender, Place and Culture, 1(2): 225-243.

Kobayashi, A. and Peake, L. 2000. Racism out of place: Thoughts on whiteness and an antiracist 
geography in the new millennium. Annals of the American Association of Geographers, 90(2): 392-403.

Kobayashi, A. 1994. Coloring the field: Gender, "race", and the politics of fieldwork. The Professional Geographer 46:73-80

Kochan, F.K. and Pascarelli, J.T. 2003. Global perspectives on mentoring. Grenwich CT: Information Age Publishing. Lagesen VA (2010) The importance of boundary objects in transcultural interviewing. European Journal of Women's Studies 17(2): 125-142.

Laliberte, N. and Bain, A. 2018. The cultural politics of a sense of failure in feminist anti-racist mentoring. Gender Place and Culture, 25(8).

Lewis, R.L. 2013. Aspiring to Greatness: West Virginia University since World War II. West Virginia University Press: Morgantown, West Virginia.

Longhurst, R. 2016. Semi-structured interviews and focus groups. In Clifford (ed). Key Methods in Geography. Sage.

Longhurst, R. 1995. The body and geography. Gender, Place \& Culture, 2(1), 97-106. https://doi.org/10.1080/09663699550022134

Lorimer, H. 2018. Dear departed: Writing the lifeworlds of place. Transactions of the Institute of British Geographers. doi:10.1111/tran.12278

Loury, L.D., and Garman, D. Affirmative action in higher education. The American Economic Review, 83(2): 99-103.

Lund, R., Kusakabe, K., Panda, S,M., and Wang, Y. Building knowledge across transnational boundaries: collaboration and friendship in research. Emotion, Space and Society.

Mahtani, M. 2006. Challenging the ivory tower: Proposing anti-racist geographies within the academy. Gender, Place and Culture, 13(1): 21-25.

Mahtani, M. 2004. Mapping race and gender in the academy: The experiences of women of color faculty and graduate students in Britain, the US and Canada. Journal of Geography in Higher Education, 21(1): 97-99.

Mahtani, M. 2002. Tricking the border guards: performing race. Environment and Planning D: Society and Space, 20(1): 425-440

Manzi, M., Ojeda, D., and Hawkins, R. 2019. "Enough wandering around!”: Life trajectories, mobility and place making in neoliberal academia. The Professional Geographer, 71(2): 355-363.

Mason, J. 2017. Qualitative Researching. SAGE: London.

Mayo, J.R., Murguia, E. and Padilla, R.V. 1995. Social integration and academic performance among minority university students. Journal of College Student Development, 36: 542552.

McDowell, L. 1993. Space, place and gender relations: Part 1. Feminist empiricism and the geography of social relations. Progress in Human Geography, 17(2): 157-179

McKenzie, A. 2012. In the Beginning: The Early History of the Divine Nine. In Brown T., Parks G., \& Phillips C. (Eds.), African American Fraternities and Sororities: The Legacy and the Vision: 183-212. University Press of Kentucky. 
McKittrick, K. 2013. Plantation futures. Small Axe, 17(3): 1-15.

McKittrick, K. 2011. On plantations, prisons, and a black sense of place. Social \& Cultural Geography, 12(8): 947-963.

2006. Demonic grounds: Black women and the cartographies of struggle.

University of Minnesota Press. Minneapolis and London.

Mee, K. and Wright, S. 2009. Geographies of belonging. Environment and Planning A, 41:772779

Minkler, M., and Robertson, A. 1991. The ideology of “Age/Race Wars": Deconstructing a social problem. Ageing and Society, 11(01), 1-22. doi:10.1017/s0144686x00003809

Minnett, J.L., James-Gallaway, A.D., and Owens, D.R. 2019. Help a sista out: Black women doctoral students' use of peer mentorship as an act of resistance. Mid-Western Educational Researcher, 31(2): 210-238

Mirza, H.S. 2014. Decolonizing higher education: Black feminist and the intersectionality of race and gender. Journal of Feminist Scholarship, 7(Fall): 1-12.

Mohanty, C.T. 1991. Third World Women and the Politics of Feminism,

Moore, F. 2018. Historical geography, feminist research and the gender politics of the present. Geography Compass

Mollett, S., and Faria, C. 2018. The spatialities of intersectional thinking: fashioning feminist geographic futures. Gender, Place \& Culture, 25(4), 565577. doi:10.1080/0966369x.2018.1454404

Moss, P. 2019. Pursuing a feminist ethos of care and the practice of mentoring. Gender Place and Culture

Moss, P. Debres, K.J., Cravey, A. Hyndman, J. Hirschboeck, K.K., and Masucci, M. 1999. Toward mentoring as feminist praxis: Strategies for ourselves and others. Journal of Geography in Higher Education, 23(3): 413-427.

Mumford, R. 1996. The role of mentoring in the college experiences of mature African American women: A qualitative investigation. Presented at the annual meeting of the American Psychological Association, Toronto, Ontario.

Nagar, R. 2014. Muddying the waters. Coauthoring feminisms across scholarship and activism. University of Illinois Press: Urbana, Chicago and Springfield.

Nakamura, J., Shernoff, D. J., Hooker, C. H., \& Csikszentmihalyi, M. (2009). Good mentoring: Fostering excellent practice in higher education. Hoboken, NJ: John Wiley \& Sons

Nash, C. 2003. Cultural geography: anti-racist geographies. Progress in Human Geography, 27(5), 637-648. doi:10.1191/0309132503ph454pr

Nelson, L. and Hiemstra, N. 2008. Latino immigrants and the renegotiation of place and belonging in small town America. Social and Cultural Geography, 9(3):319-342

Nembhard, J.G. 2014. Collective Courage: A history of African American cooperative economic thought and practice. The Pennsylvania State University Press: University Park, PA.

Neumann, C. 2008. Black Feminist Thought in Black Sororities. In Malveaux J. \& Morial M. (Authors) \& Parks G. (Ed.), Black Greek-letter Organizations in the Twenty-First 
Century: Our Fight Has Just Begun:169-186. University Press of Kentucky.

Nightingale, A. J. 2011. Bounding difference: Intersectionality and the material production of gender, caste, class and environment in Nepal. Geoforum, 42(2), 153-

162. doi:10.1016/j.geoforum.2010.03.004

Norwood, C. 2013. Perspective in Africana feminism; Exploring expressions of Black feminism/womanism in the African Diaspora. Sociology Compass, 7(3), 225-236. doi:10.1111/soc4.12025

Oberhauser, A.M. and Caretta, M.A. 2019. A space for feminist mentoring: the role of Geographic Perspectives on Women (GPOW) specialty group in higher education. Gender Place and Culture, 26(12): 1664-1682

Parks, G.S. and Hernandez, M. 2016. Fortitude in the face of adversity: Delta Sigma Theta's history of racial uplift. Hastings Race and Poverty Law Journal, 13(2): 273-347.

Patton, L.D. and Harper, S. R. 2003. Mentoring relationships among African American women in graduate and professional schools. New Directions for Student Services 104: Winter 2003: 67-78

Phillips, C.M. 2005. Sisterly bonds: African American sororities rising to overcome obstacles. African American Fraternities and Sororities: The Legacy and Vision: 342-359. University Press of Kentucky

Pope, E.C. and Edwards, K.T. 2016. Curriculum homeplacing as complicated conversation: (re)narrating the mentoring of Black women doctoral students. Gender and Education, 28(6): 769-785

Pratt, G., \& Hanson, S. 1994. Geography and the construction of difference. Gender, Place \& Culture, 1(1), 5-29. doi:10.1080/09663699408721198

Price, A. 2019. Spell it with a capital "B". Insight Center for Community Economic Development. Retrieved May 5, 2020. (https://medium.com/@InsightCCED/spell-itwith-a-capital-b-9eab112d759a)

Pulido, L. 2002. Reflections on a white discipline. The Professional Geographer, 54(1): 42-49.

Roche, M. 2005. Historical research and archival resources. Qualitative Research Methods in Human Geography, 2: 225-45

Rose, G. 1997. Situating knowledges: positionality, reflexivities and other tactics. Progress in Human Geography, 21(3), 305-321. https://doi.org/10.1191/030913297673302122

Rose, G. 1993. Feminism and geography: An introduction. In Feminism and geography: The limits of geogragraphical knowledge (pp. 1-16). University of Minnesota Press.

Roth, B. 2004. Separate roads to feminism: Black, Chicana, and White movements in America's second wave. New York: Cambridge University Press.

Ruddick, S. 1996. Constructing difference in public spaces: Race, class, and gender as interlocking systems. Urban Geography, 17:132-151

Sands, R.G., Parson, A., and Duane, J. 1991. Mentoring faculty in a public university. Journal of Higher Education. 62(2):174-193

Sapp, V. 2016. Social networks beyond the baccalaureate: a case study of first-generation Black 
women graduates' experiences in an alumnae chapter of a historically black sorority. (Dissertation).

Schurr, C. and Segebart, D. 2012. Engaging with feminist postcolonial concerns through participatory action research and intersectionality. Geographica Helvetica, 67:147-154.

Shabazz,R. 2015. Spatializing Blackness: Architectures of Confinement and Black Masculinity in Chicago. University of Illinois Press.

Smith, N. 1990. Geography, difference and the politics of scale. In Postmodernism and the Social Sciences, J. Doherty, E. Graham, and M. Malek (eds). New York. Saint Martin's Press.

Smith, W.A., Hung, M. and Franklin, J.D. 2011. Racial battle fatigue and the miseducation of Black men: Racial microaggressions, societal problems, and environmental stress. The Journal of Negro Education 80(1): 63-82

Sorcinelli, M.D. and Yun, J. 2007. From mentor to mentoring networks: Mentoring the new academy. The Magazine of Higher Education. 57-61.

Spivak, G.C. Can the subaltern speak? In: Nelson, and L. Grossberg (eds). Marxism and the interpretation of culture, Macmillian Education: Basingstoke

Stam, R. and Shohat, E. Race in translation: Culture wars around the postcolonial Atlantic. NYU Press: New York.

Stoetzler, M. and Yuval-Davis, N. 2002. Standpoint theory situated knowledge and the situated imagination. Feminist Theory. Sage. Thousand Oaks California

Tatum, B.D. 1997. Racial identity development and relational theory: The case of Black women in white communities. Women's growth in diversity: More writings from the Stone Center, New York. Guilliford Press.

Thorn, E.A. 2014. A qualitative examination of the support systems impacting the African American student persistence, retention and graduation at a predominately white research extensive, land-grant Midwest university. (Dissertation) Retrieved from https://mospace.umsystem.edu/xmlui/bitstream/handle/10355/44507/research.pdf?sequence=1

Tindall, N.T., Hernandez, M. and Hughey, M.W. 2011. Doing a good job at a bad thing: Prevalence and perpetuation of stereotypes among members of historically Black sororities. Oracle: The Research Journal of the Association of Fraternity/Sorority Advisors. 6(2): 36-53

Tuan, Y. 1997. Space and Place: The Perspective of Experience. University of Minnesota Press. Minneapolis.

U.S. Department of Education, National Center for Education Statistics. (2019). The Condition of Education 2019 (NCES 2019-144), Characteristics of Postsecondary Faculty.

Valentine, G. 2005. Geography and ethics: moral geographies? Ethical commitment in research and teaching. Progress in Human Geography, 29(4), 483-487. doi:10.1191/0309132505ph561pr

Vance, K.M. 2019. National Pan-Hellenic council membership on the predominately white yard: 
The development of sense of belonging and social capital for underrepresented students attending a predominately white institution. (Dissertation). Retrieved from:

https://search.proquest.com/docview/2350928356?pq-origsite=gscholar

Walker, A. [1979] 2003. Coming apart: In L. Phillips (Ed.), The Womanist Reader, pp 3-11. New York, NY. Taylor and Francis

------- [1967] 2003. In search of our mother's gardens: Womanist prose. Orlando, FL. Harcourt Books.

Wallace, M. 1999. The Culture War within the Culture Wars: Race. In Art Matters: How the Culture Wars changed America. Wallis, B., Weems, M., and Yenawine, P. (eds). New York: New York University Press.

Watch the Yard, 2019. The story of how the first white member of Delta Sigma Theta was a segregationist's worst nightmare. Retrieved from, https://www.watchtheyard.com/deltas/joan-mulholland-delta-sigma-theta-white-member/

Watson, C. A., \& Till, K. E. 2015. The SAGE handbook of qualitative geography:

Ethnography and participant observation, 121-137. https://doi.org/10.4135/9780857021090.n9

Webster, N. and Boyd, M. 2018. Exploring the importance of inter-departmental women's friendship in geography as resistance in the neoliberal academy. Geografiska Annaler: Series B, Human Geography. DOI: 10.1080/04353684.2018.1507612

Webster, N. \& Caretta, M.A. 2019. Early-career women in geography. Practical pathways to advancement in the neoliberal university, Geografiska Annaler: Series B, Human Geography, 101:1, 1-6, DOI: 10.1080/04353684.2019.1571868

West Virginia University, Division of Diversity, Equity and Inclusion. 2018. Current Diversity Initiatives. [https://diversity.wvu.edu/diversity-initiatives]. 1950-1970. The Monticola. West Virginia University Libraries. Chicago, A.L. Swift \& Co.

West Virginia University, Women's Studies Center, Women's Centenary, Records, West Virginia and Regional History Center, West Virginia University Libraries. A\&M 3376

Whaley, D.E. 2010. Disciplining women: Alpha Kappa Alpha, Black counter publics, and the cultural politics of Black sororities. SUNY Press: New York

Whipple, E., Crichlow, M., \& Click, S. 2008. Black and White Greeks: A call for collaboration. In Malveaux J. \& Moria. Fl M. (Authors) \& Parks G. (Ed.), Black Greekletter Organizations in the Twenty-First Century: Our Fight Has Just Begun (pp. 421436). University Press of Kentucky.

Wilkerson, M.B. 1984. 'Lifting as we climb: Networks for minority women". In A. Tinsley, C. Secor, and S. Kaplan (eds). Women in Higher Education. San Fransciso: Jossey-Bass.

Williams, A., \& Crooks, V. A. 2008. Introduction: space, place and the geographies of women's caregiving work. Gender, Place \& Culture, 15(3), 243-247. doi:10.1080/09663690801996254

Yin, R. K. 2013. Validity and generalization in future case study evaluations. Evaluation, 19(3), 321-332. doi:10.1177/1356389013497081 
Yuval-Davis, N. 2006. Belonging and the politics of belonging. Patterns of Prejudice, 40(3): 197-214 